\title{
A Modular Framework for Modeling Unsaturated Soil Hydraulic Properties Over the Full Moisture Range
}

Weber, Tobias K.D.; Durner, Wolfgang; Streck, Thilo; Diamantopoulos, Efstathios

Published in:

Water Resources Research

DOI:

10.1029/2018WR024584

Publication date:

2019

Document version

Publisher's PDF, also known as Version of record

Citation for published version (APA):

Weber, T. K. D., Durner, W., Streck, T., \& Diamantopoulos, E. (2019). A Modular Framework for Modeling

Unsaturated Soil Hydraulic Properties Over the Full Moisture Range. Water Resources Research, 55(6), 49945011. https://doi.org/10.1029/2018WR024584 


\section{Water Resources Research}

\section{RESEARCH ARTICLE 10.1029/2018WR024584}

Key Points:

- A modular framework to describe soil hydraulic properties over the entire moisture range in soils is presented

- Compared to the classical van Genuchten-Mualem approach, only one additional model parameter is required

- We demonstrated suitability by excellent model descriptions of measured water retention and hydraulic conductivity data sets

Supporting Information:

- Supporting Information S1

- Figure S1

- Figure S2

- Figure S3

- Figure S4

- Figure S5

- Figure S6

- Data Set S1

- Data Set S2

- Data Set S3

Correspondence to:

T. K. D. Weber,

tobias.weber@uni-hohenheim.de

Citation:

Weber, T. K. D., Durner, W., Streck, T., \& Diamantopoulos, E. (2019). A modular framework for modeling unsaturated soil hydraulic properties over the full moisture range. Water Resources Research, 55, 4994-5011. https://doi.org/10.1029/2018WR024584

Received 21 DEC 2018 Accepted 29 MAR 2019 Accepted article online 3 APR 2019 Published online 24 JUN 2019

2019. American Geophysical Union. All Rights Reserved.

\section{A Modular Framework for Modeling Unsaturated Soil Hydraulic Properties Over the Full Moisture Range}

\author{
Tobias K. D. Weber ${ }^{1}$ iD, Wolfgang Durner ${ }^{2}$ iD, Thilo Streck ${ }^{1}$ iD, and Efstathios Diamantopoulos ${ }^{3}$ iD \\ ${ }^{1}$ Institute of Soil Science and Land Evaluation, University of Hohenheim, Stuttgart, Germany, ${ }^{2}$ Institute of Geoecology, \\ Division of Soil Science and Soil Physics, Braunschweig University of Technology, Braunschweig, Germany, ${ }^{3}$ Department \\ of Plant and Environmental Science, Section of Environmental Chemistry and Physics, University of Copenhagen, \\ Frederiksberg, Denmark
}

Abstract A generalized modular framework for partitioning soil hydraulic property (SHP) functions into a capillary and a noncapillary part is developed. The full water retention curve (WRC) is modeled as a weighted sum of a parametric capillary saturation function and a new general model for the noncapillary saturation function. This model is directly computed from any selected capillary saturation function. With it, a physically complete, continuous, and flexible representation of the WRC is achieved, ensuring zero water content at oven dryness. In a modular and hierarchical framework, the expressions for the capillary and noncapillary saturation function are used to calculate the respective hydraulic conductivity curves (HCC). This is achieved by adopting Mualem's integral for the capillary part of the HCC only and calculating the noncapillary HCC directly from the new noncapillary saturation function. This leads to consistent descriptions of measured HCC data, including the often observed change in slope beyond $-100 \mathrm{~cm}$ pressure head. Compared to the classical van Genuchten-Mualem approach, it requires only one additional model parameter. The SHP framework model describes both WRC and HCC adequately and coherently. We demonstrate the suitability of the SHP framework and versatility by describing measured WRC and HCC data across the full moisture range using soil samples from a wide range of textures and origins. The modular framework was implemented in the soil physics and soil hydrology (spsh) R-package, available from the Comprehensive R Archive Network. It contains several SHP models, model parameter estimation, and features options for goodness of fit statistics, and model selection.

Plain Language Summary Soils are important features of the landscape and provide many ecosystem services related to food production and clean water. Most of the terrestrial life depends in some way or the other on this biologically, chemically, and physically highly active and complex environment. Soil water is a connecting factor linking most of the soils' properties. In order to predict a soil's ability to store and conduct water, mathematical models have been developed. These are commonly referred to as (effective) soil hydraulic property functions. Most commonly, the hydraulic property functions from van Genuchten and Mualem have been used, but these models have widely acknowledged deficiencies. In this study, we develop a modular framework model that overcomes some core deficiencies. The improvements are demonstrated by comparison with measured soil hydraulic properties from soils. We expect the framework model to have a considerable impact in increasing the precision and accuracy in predictions of water movement and evaporation from soils and ultimately crop growth.

\section{Introduction}

Vadose zone properties control most biotic and abiotic subsurface and near-surface processes, including evaporation, infiltration, and water redistribution, energy partitioning, solute transport, and matter turnover in the groundwater-soil-plant-atmosphere continuum (Field et al., 2015; Kirkby, 2016; Lin, 2014). Moreover, 8 out of the 17 UN Sustainable Development Goals are directly or indirectly related to current research questions in hydropedology (Bouma, 2016), by ecosystem services that the vadose zone provides to human livelihoods (Field et al., 2015; Lin, 2014). Manifesting the importance of vadose zone hydrology in the scientific community, large monitoring networks such as Critical Zone Observatories (White et al., 2015) and Terrestrial Environmental Observatories (Bogena et al., 2016) have been established in recent years (Guo \& Lin, 2016). Mathematical models are indispensable to understanding the complex biological, chemical, and physical feedbacks necessary to tackling global challenges such as climate change, the food 
security problem (Asseng et al., 2013), insufficient drinking water quantity and quality (Jury \& Vaux, 2005), and the leaching of agrochemicals to ground and surface water (Diamantopoulos et al., 2017). Models enable the exploration of the fundamental processes, testing of hypotheses, and predicting trajectories of developments (Vereecken et al., 2016).

Essential to vadose zone research is the correct representation of the moisture state. For this, numerical simulations of transient unsaturated moisture dynamics in soils frequently adopt a combination of the Buckingham-Darcy equation with the continuity equation, independently proposed by Richardson (1922) and Richards (1931), which is arguably the most commonly used process model in the area today (Beckie, 2006). The Richards equation (RE; Richards, 1931) relies on the concept of the representative elementary volume enabling a volume-averaged continuum description of the pressure-dependent state of soil water retention and conductivity (Assouline \& Or, 2013). These constitutive relationships are reflected in the soil hydraulic properties (SHP) of the water retention curve (WRC) and the hydraulic conductivity curve (HCC). Accurate knowledge of the SHP is required for reliable modeling of water fluxes and solute transport in unsaturated soils (Durner \& Flühler, 2006).

Theories as well as parametric functions describing SHP have been reviewed in detail elsewhere (e.g., Assouline \& Or, 2013; Coppola, 2000; Cornelis et al., 2005; Khlosi et al., 2008; Kosugi et al., 2002; Leij et al., 1997), and even more research papers give detailed accounts in their introductions (e.g., Madi et al., 2016; Peters, 2013; Rudiyanto et al., 2015). For this reason, we have limited ourselves to an epitome of the matter.

The most widely used set of SHP functions was formulated by van Genuchten (1980), typically referred to as the van Genuchten-Mualem (VGM) model. Essentially, the VGM conceptualizes the water storage and conductance in soils to take place in completely filled capillaries (Mualem, 1976a). In spite of its usefulness, a number of authors have pointed out four main shortcomings:

The first shortcoming addresses the inability of the VGM to describe the dry end of the WRC (Assouline \& Or, 2013; Nimmo, 1991) and the HCC, properly. A number of effective amendments have been proposed for the WRC by Fayer and Simmons (1995), Lebeau and Konrad (2010), and Khlosi et al. (2006). For the HCC, examples are the corrections by Peters and Durner (2008) and those summarized in Assouline and Or (2013). Figure 1 highlights this shortcoming by showing the discrepancy between measured and VGM-modeled WRC. Two cases are considered: one where the parameter for the residual water content was set to 0 (Figure 1a) and the other where it is treated as an additional free parameter in the calibration process (Figure 1c). Both cases lead to an inadequate description of the measured WRC data, but also to the modeled HCC as shown in Figures $1 \mathrm{~b}$ and $1 \mathrm{~d}$. The discrepancy can partially be associated to a misrepresentation of modeled soil water assumed to only be stored in capillaries (Diamantopoulos \& Durner, 2013, 2015; Tuller \& Or, 2001). This realization has led to diverse formulations partitioning water storage and flow into capillary and noncapillary parts (Lebeau \& Konrad, 2010; Peters, 2013; Zhang, 2011).

The second shortcoming concerns structural deficits in describing multimodal pore size distribution (PSD). These deficits have been resolved by introducing flexible expressions suited to describe multimodal PSD (Iden \& Durner, 2007; Othmer et al., 1991). The most successful approach for mineral and organic soils has proven to be superpositioning weighted unimodal WRC functions (Durner, 1992; Durner, 1994; Mallants et al., 1997; Romano \& Nasta, 2016; Ross \& Smettem, 1993; Weber et al., 2017a, 2017b; Wilson et al., 1992).

The third shortcoming relates to the finding that the VGM model may be inadequate to describe the HCC near saturation. The proposed corrections are simple and straightforward modifications, often to the VGM model (Schaap \& van Genuchten, 2006; Vogel et al., 2000) or to the HCC model by introducing an empirical expression for macropores and thereby replaces the Young-Laplace law for this pore domain (Iden et al., 2015).

The fourth shortcoming relates to hysteresis in the capillary and noncapillary parts of the WRC. To cope with this phenomenon a few models have been developed (Kool \& Parker, 1987; Lenhard \& Parker, 1987; Rudiyanto et al., 2015). For completeness, we point out that inadequate descriptions of the underlying SHP may not only lead to discrepancies between observed and simulated experimental data but also question the applicability of the RE. For example, if nonequilibrium effects play a role at the scale of 

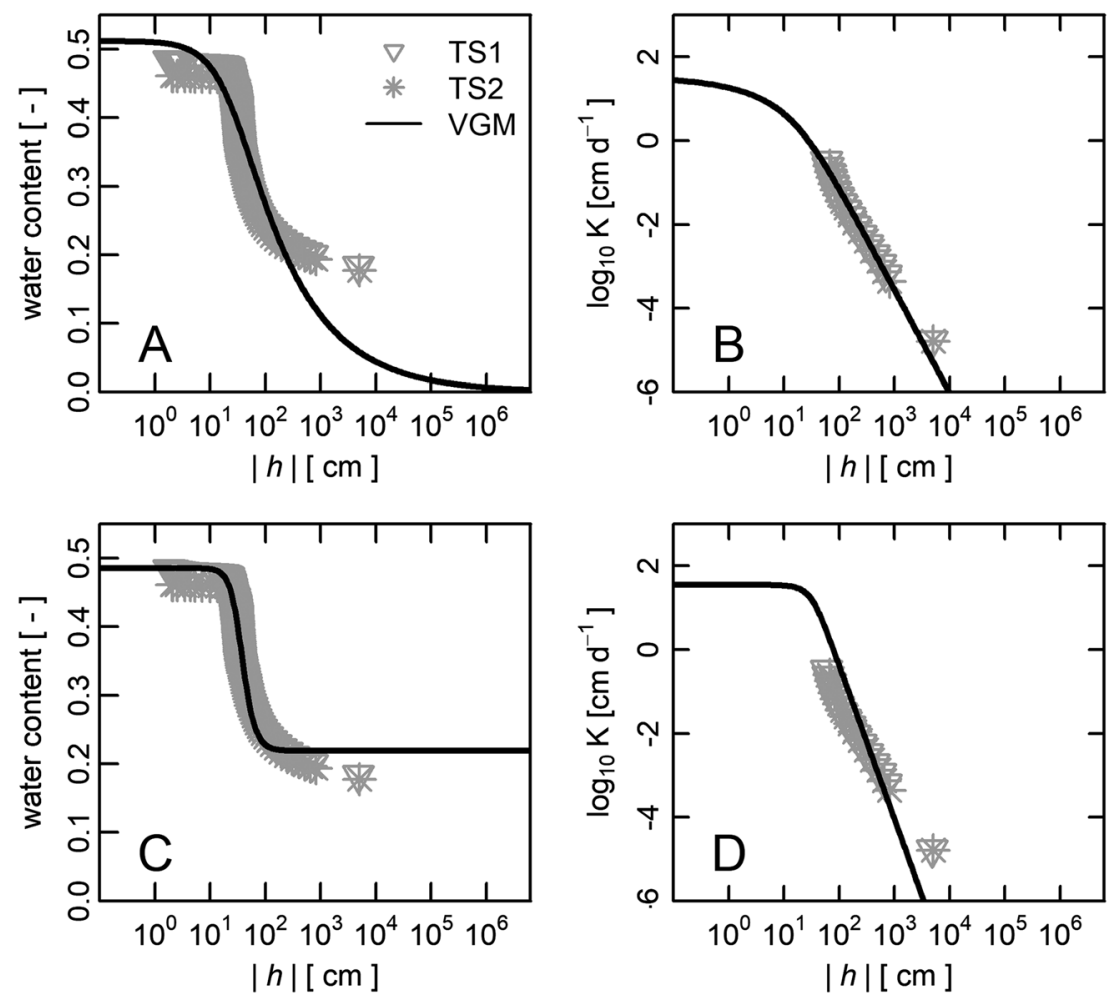

Figure 1. Illustration of the structural mismatch between measured data from an evaporation experiment on two samples from a tailing sand (TS; experimental details in Appendix A). First, the residual water content is fixed to the physically plausible value of $0 \mathrm{~cm}^{3} / \mathrm{cm}^{3}$ at a pressure head corresponding to oven dryness (top row; the respective water retention curve [a] and the hydraulic conductivity curve [b]). Second, it was fixed to the estimated optimum parameter (bottom row; the respective water retention curve [c] and the hydraulic conductivity curve [d]). VGM = van Genuchten-Mualem.

application this would require explicit representation (Diamantopoulos et al., 2012; Diamantopoulos \& Durner, 2012; Šimůnek et al., 2003).

To overcome these shortcomings, a vast number of models have been formulated in the course of the past decades, leading to a mosaic of effective SHP models. Moreover, outside the soil hydrological community, numerical simulations of unsaturated soils with the RE heavily rely on outdated SHP parameterizations such as the Clapp and Hornberger equation (Chen et al., 2016; Clapp \& Hornberger, 1978).

From this we derived two aims for this study. First, we propose an elegant and parsimonious solution to model also the dry end of the WRC. It is based on a generalized method to obtain a function for the noncapillary saturation from any capillary saturation model. Second, we embed this function into a unifying modular framework for the specification of the SHP models, which we present as a hierarchal flowchart. This modularity provides a high level of flexibility in model choice, and serves didactical and practical purposes.

We have structured the paper as follows: In section 2, we present the concept of the modular SHP framework and the holistic expression for the noncapillary saturation function. In section 3, the framework model (FM) is tested against measured WRC and HCC data, demonstrating the versatility of the FM. This is exemplified by adopting the VGM model components as the building blocks for capillary retention and conductivity. The results are presented and discussed in section 4. Finally, section 5 gives a summary and conclusion. In Appendix B, we list 12 isothermal vapor conductivity models and in the supporting information (SI) two alternatives to the van Genuchten VG saturation model, which illustrate the versatility of the newly developed method to model the noncapillary saturation function within our FM. 


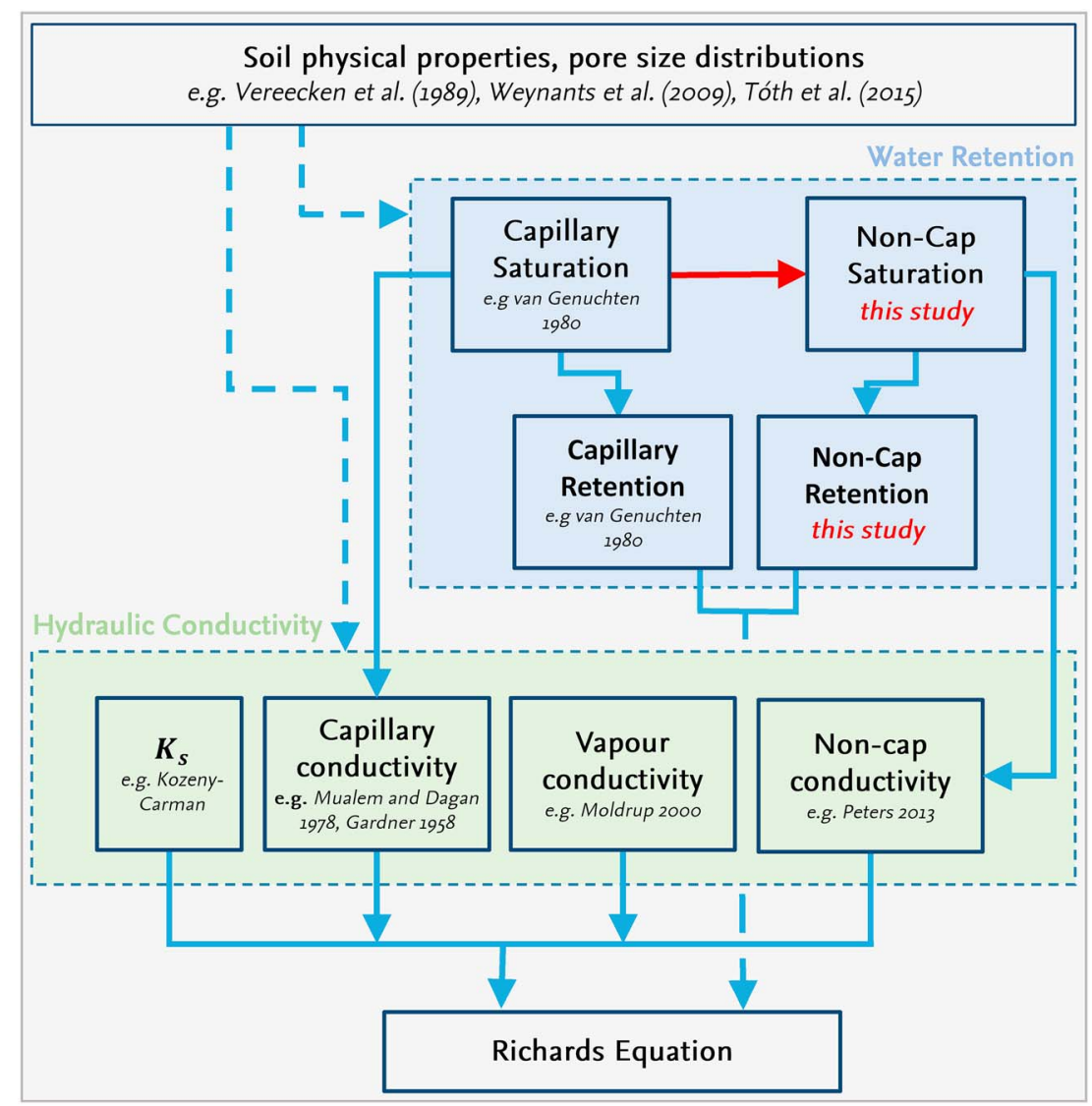

Figure 2. Modular flow chart depicting the building blocks (boxes) for the representation of the soil hydraulic properties necessary to numerically simulate water flow in unsaturated soils with the Richards equation. Mathematical operations are shown as blue arrows. New parts in this study are given in red. $K_{S}$ is the saturated hydraulic conductivity. The soil physical properties and pedotransfer functions exist to, among others, make assumption on pore size distributions, but mostly specific formulations exit to directly predict soil hydraulic data or model parameters (dashed blue arrows).

\section{Theoretical Development}

\subsection{Conceptual Framework of SHP Models}

The modularity of the conceptual framework is illustrated by the flowchart in Figure 2. Often, pedotransfer functions, indicated by the dashed arrows on the top left of the flowchart, are used to relate soil physical properties to the parameters of soil hydraulic functions by statistical methods. SHP parameters are predicted from, among others, soil texture, soil organic matter, and bulk density (e.g., Schaap \& Leij, 2000; Scharnagl et al., 2011; Tóth et al., 2015; Vereecken et al., 1989; Weynants et al., 2009). Assuming the validity of the Young-Laplace law, the flow chart follows the general idea that the basis of any parameterization of the $\mathrm{RE}$ is an effective representation of the pore size distribution ( $f(r), \mathrm{PSD})$ of a rigid soil.

While the size and configuration of the soil pores determine the PSD (Nimmo, 2004), researchers have long argued that not all water can be conceptualized as stored and conducted in capillaries (Assouline \& Or, 2013; Diamantopoulos \& Durner, 2013; Tuller \& Or, 2001). In our framework this is reflected by partitioning into a capillary and a noncapillary part (Figure 2, second row). The new feature introduced in this study is that the noncapillary saturation function is directly determined from the shape of the capillary saturation part. Based on the two component saturation function, the full expressions for the WRC and HCC are then modeled following the flowchart (Figure 2, second and third rows). The full WRC and HCC are, respectively, finally obtained by summation of their components. Figure 2 shows two further components; one representing the saturated conductivity, $K_{S}$, the other the isothermal vapor conductivity. $K_{S}$ may be derived from soil permeability reflecting the PSD and pore connectivity, for which a number of equations have been postulated, 
best known are the Kozeny-Carman equation and derivations thereof (Green et al., 2003). Alternatively, $K_{s}$ can be interpreted as a measurable parameter determined by experiments. Lastly, $K_{S}$ may be determined by inverse modeling (Hopmans et al., 2002). Classically, only liquid water is considered in the RE. However, under isothermal conditions the vapor diffusion can be treated as part of an effective total water conductivity. Following Saito et al. (2006), this conductivity component is obtained from knowledge of the basic physical properties of water, and relations of soil air content and pore tortuosity. In the appendix (Table B1), we list 12 models for the tortuosity, leading to model variants for the isothermal vapor conductivity. A high-resolution image of the framework in Figure 2 is presented in the SI.

\subsection{Mathematical Implementation of the Framework}

\subsubsection{Retention Model}

The soil water retention $\theta(-)$ is a function of pressure head $h(\mathrm{~L})$. As a sum of the capillary $S_{\mathrm{c}}(h)(-)$ and noncapillary $S_{\mathrm{nc}}(h)(-)$ saturation function it is given by

$$
\theta(h)=\theta_{\mathrm{cs}} S_{\mathrm{c}}(h)+\theta_{\mathrm{ncs}} S_{\mathrm{nc}}(h)
$$

where $\theta_{\mathrm{cs}}(-)$ and $\theta_{\mathrm{ncs}}(-)$ are the saturated water contents of the capillary and the noncapillary parts, respectively. In analogy to the classical notation found in the literature, the saturated water content, $\theta_{s}$ $(-)$, is the sum of $\theta_{\mathrm{cs}}$ and $\theta_{\text {ncs. }}$.

$$
\theta_{s}=\theta_{\mathrm{cs}}+\theta_{\text {ncs }}
$$

2.2.1.1. Saturation Function for Completely Filled Capillaries

Various expressions have been suggested in the literature to describe the effective SHP. In the VG model, among others, a water content of 0 at pressure heads corresponding to oven dryness is not ensured (Fredlund \& Xing, 1994; Rudiyanto et al., 2015). For this reason, we adopt the rescaling approach introduced by Iden and Durner (2014). The effective saturation function $S_{\mathrm{c}}(h)$ is given by

$$
S_{\mathrm{c}}(h)=\frac{\Gamma(h)-\Gamma_{0}}{1-\Gamma_{0}}
$$

where $\Gamma(h)$ is the saturation function and $\Gamma_{0}$ is $\Gamma(h)$ at oven dryness where $\theta=0$. Suggested by Schneider and Goss (2012) and in agreement with literature values, it is set to $h_{0}=-10^{6.8} \mathrm{~cm}$ (Iden et al., 2015; Volk et al., 2016; Weber et al., 2017a, 2017b). The exact value can be determined experimentally using, for example, oven dried soil and the dewpoint (DP) method (Gee et al., 1992).

Importantly, the rescaling of $\Gamma(h)$ permits the generic expression of $S_{\mathrm{c}}(h)$ in equation (3) and can be replaced by any proposed saturation equation, among others, Campbell and Shiozawa (1992), Ross and Smettem (1993), Kosugi (1994, 1996), Fredlund and Xing (1994), Rossi and Nimmo (1994), Weiss et al. (1998), the VG and VG-type functions (Kosugi et al., 2002; van Genuchten, 1980). A case study using the VGM model is shown in the results section, and examples of the Kosugi, and Fredlund and Xing models within the framework can be found in the SI.

\subsubsection{New Noncapillary Saturation Function}

The remaining, noncapillary water content decreases nearly linearly toward 0 on the semi- $\log _{10}$ scale in the dry end of the WRC (Campbell \& Shiozawa, 1992; Riedel \& Weber, 2016; Schneider \& Goss, 2012). To model this behavior, Peters (2013) slightly modified an originally proposed model by Fredlund and Xing (1994), to describe the pressure head-noncapillary saturation function $S_{\mathrm{nc}}(h)$ [-]. This is achieved by modeling $S_{\mathrm{nc}}(h)$ as a piecewise function, similar to the Brooks-Corey saturation model (Brooks and Corey, 1964). For this, an extra model parameter for an explicit air entry pressure head $h_{a}(\mathrm{~cm})$ was introduced by Peters (2013) so that $\forall h>h_{a}$, the relationship $S_{\mathrm{nc}}(h)=1$ holds. This parameter is chosen to ensure that the modeled noncapillary water cannot be extracted from the soil before the capillary water. As a result, the function is not continuously differentiable at $h_{a}$, because of the associated discontinuity of the soil water capacity function at $h_{a}$ (see also Iden \& Durner, 2014), and it introduces an additional model parameter.

To alleviate these problems, we introduce a new model for $S_{\mathrm{nc}}(h)$. We require that $S_{\mathrm{nc}}(h)$ is (i) continuously differentiable over the entire pressure head range, (ii) is unity close to the air entry pressure head and decreases more slowly than $S_{\mathrm{c}}(h)$ on the wet end of the WRC, (iii) decreases log-linearly to 0 on the dry end, and (iv) that all this is achieved without introducing an extra model parameter. This new model computes $S_{\mathrm{nc}}(h)$ directly from the modularly exchangeable $S_{\mathrm{c}}(h)$. The desired properties are obtained by 


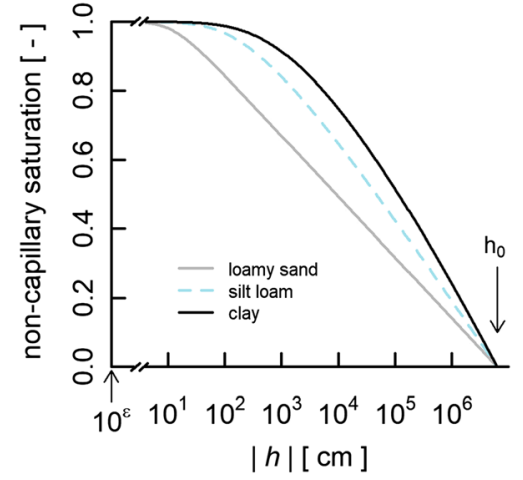

Figure 3. Examples of the noncapillary saturation function for three common soils with a wide texture range from the Carsel and Parish Soil Catalogue (loamy sand, silt, and clay): On the semi- $\log _{10}$ scale, the function is close to linear in the high $\mathrm{pF}$ range. integrating $S_{\mathrm{c}}(h)-1$ in $p F$ space, where $p F=\log _{10}(-h)$, and rescaling the resulting function to values between unity and 0 . In an initial step we derive $S_{\mathrm{nc}}^{*}(h)$ from

$$
S_{\mathrm{nc}}^{*} p F(p F)=\int_{\epsilon}^{p F}\left(S_{\mathrm{c}}^{p F}\left(p F^{\prime}\right)-1\right) \mathrm{d} p F^{\prime}
$$

where $\epsilon=\log _{10}\left(-h_{\epsilon}\right), S_{\mathrm{c}}^{p F}(p F)=S_{\mathrm{c}}\left(-10^{\mathrm{pF}}\right)$, and $\mathrm{d} p F^{\prime}$ is the dummy variable of integration. The pressure head, $h_{\epsilon}(\mathrm{cm})$, is a fixed pressure head very close to 0 , which is necessary because the integral cannot be numerically evaluated at zero pressure head. For example, we may choose $h_{\epsilon}=-10^{-3} \mathrm{~cm}$, leading to $\epsilon=-3$.

Equation (4) can be transformed to normal space by substituting $p F$ by $h$. Using the relationship

$$
\frac{\mathrm{d} p F}{\mathrm{~d} h}=-\log _{10}(e) \frac{1}{h}
$$

yields

$$
S_{\mathrm{nc}}^{*}(h)=\log _{10}(e) \int_{h}^{-10^{\epsilon}} \frac{S_{\mathrm{c}}\left(h^{\prime}\right)-1}{h^{\prime}} \mathrm{d} h^{\prime}
$$

where $e$ is Euler's number and $h^{\prime}$ the dummy variable of integration.

In the second step, we rescale the function $S_{\mathrm{nc}}^{*}(h)$ by

$$
S_{\mathrm{nc}}(h)=1-\frac{S_{\mathrm{nc}}^{*}(h)}{S_{\mathrm{nc}}^{*}\left(h_{0}\right)}
$$

which ensures that $S_{\mathrm{nc}}(h)$ scales between 0 and 1 when $h$ varies between $\varepsilon$ and $h_{0}=-10^{6.8} \mathrm{~cm}$. Figure 3 illustrates examples of $S_{\mathrm{nc}}(h)$, computed for typical soils (loamy sand, silt, and clay) as examples for the model behavior for soils with widely contrasting textures. These are taken from the Carsel and Parish soil catalogue (Carsel \& Parrish, 1988) and demonstrate the desired near linear $p F$-noncapillary saturation relationship toward the dry end. As demonstrated in Figure $4, S_{\mathrm{nc}}(h)$ will in general drop more slowly than $S_{\mathrm{c}}(h)$ as the pressure head decreases. The mathematical justification for this desired behavior is given in Appendix C.

The fact that, regardless of the chosen model $S_{\mathrm{c}}(h)$, the new integral approach for $S_{\mathrm{nc}}(h)$ introduces no extra parameter is a clear advantage over the modification of the Peters (2013) model by Iden and Durner (2014). As a consequence of the normalization in equation (7), $S_{\mathrm{nc}}\left(h_{\epsilon}\right)$ is unity, and therefore, it is continuously extendable with unity and $S_{\mathrm{nc}}\left(h \geq h_{\epsilon}\right)=1$ holds true. Moreover, it is ensured that $S_{\mathrm{nc}}\left(h_{0}\right)=0$. The similarity to the scaled integral expression of Mualem's capillary bundle model becomes evident, when $S_{\mathrm{nc}}^{*}\left(h_{0}\right)$ in equation (7) is written explicitly as $\log _{10}(e) \int_{h_{0}}^{h_{\varepsilon}} \frac{S_{c}\left(h^{\prime}\right)-1}{h^{\prime}} \mathrm{d} h^{\prime}$.

\subsubsection{Model of the Hydraulic Conductivity}

In general, water flow in soils may occur in its liquid and vapor states (Nassar \& Horton, 1989; Noborio et al., 1996). Since the soil water retention in this framework is partitioned into conceptually two different pore regions, this has to be reflected in the total hydraulic conductivity function $K_{\text {tot }}(h)(\mathrm{L} / \mathrm{T})$ which is given by the sum

$$
K_{\mathrm{tot}}(h)=K_{\mathrm{c}}(h)+K_{\mathrm{nc}}(h)+K_{\mathrm{ivc}}(h)
$$

where $K_{\mathrm{c}}(h)(\mathrm{L} / \mathrm{T})$ is the hydraulic conductivity of liquid water in completely filled capillaries, $K_{\mathrm{nc}}(h)(\mathrm{L} / \mathrm{T})$ is the hydraulic conductivity of the noncapillary liquid water, and $K_{\mathrm{ivc}}(h)(\mathrm{L} / \mathrm{T})$ is the isothermal water vapor conductivity. Since $K_{\mathrm{ivc}}$ dominates $K_{\mathrm{tot}}$ only at very low pressure heads, where the gravitational force may be ignored in the RE, the approximation is valid as stated (Peters, 2013). We purposely exclude a further 

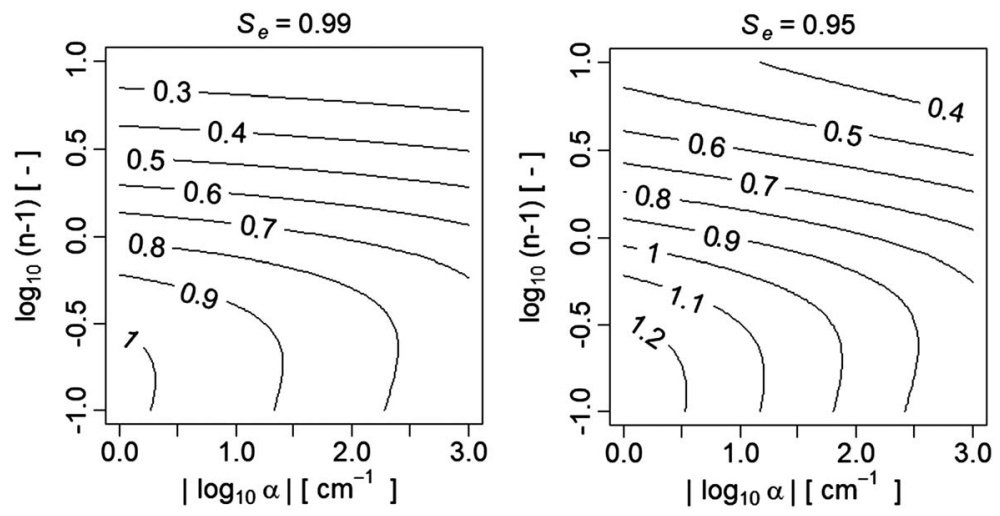

Figure 4. Contours illustrating the difference in $\mathrm{pF}$ at which a specific degree of saturation of the noncapillary and capillary saturation, $S_{\mathrm{nc}}(h)$ and $S_{\mathrm{c}}(h)$, occurs, where positive values indicate that $S_{\mathrm{c}}(h)$ drops quicker with increasing $\mathrm{pF}$ than $S_{\mathrm{nc}}(h)$. Saturation levels $\left(S_{e}=0.99\right.$; left and $S_{e}=0.95$; right). This is shown for $\sim 10^{4}$ parameter combinations of the van Genuchten shape parameters $\alpha$ and $n$.

treatment of the isothermal vapor conductivity in the main text and explore the topic in Appendix B, where we report on various tortuosity models and the associated calculation of vapor diffusivity.

The total liquid hydraulic conductivity $K(h)(\mathrm{L} / \mathrm{T})$ is partitioned by the following weighted sum expression similar to Peters (2013)

$$
K\left(S_{\mathrm{c}}, S_{\mathrm{nc}}\right)=K_{\mathrm{sc}} K_{\mathrm{rc}}\left(\mathrm{S}_{\mathrm{c}}\right)+K_{\mathrm{snc}} K_{\mathrm{rnc}}\left(\mathrm{S}_{\mathrm{nc}}\right)
$$

where $K_{\mathrm{rc}}\left(S_{\mathrm{c}}\right)$ is the relative hydraulic conductivity associated to completely filled capillaries as described by equation (3) and, analogously, $K_{\mathrm{rnc}}\left(S_{\mathrm{nc}}\right)$ is the saturation dependent relative conductivity of the noncapillary part. To facilitate readability, $h$ is dropped in the notations in equations (9)-(11). Further, $K_{S}(\mathrm{~L} / \mathrm{T})$ is the traditional total saturated hydraulic conductivity, which is partitioned into the saturated capillary conductivity, $K_{\mathrm{sc}}$, and the noncapillary conductivity $K_{\mathrm{snc}}$, which means only one extra free parameter is introduced, compared to the VGM model.

\subsubsection{Hydraulic Capillary Conductivity Model}

A generalized capillary bundle model for the prediction of unsaturated hydraulic conductivity $K(h)$ from $\Gamma(h)$ is given by Mualem and Dagan (1978) and Hoffmann-Riem et al. (1999) as

$$
K_{\mathrm{rc}}\left(S_{c}\right)=\Gamma^{\tau}\left[\frac{\int_{\Gamma_{0}}^{\Gamma} h^{-q} \mathrm{~d} u}{\int_{0}^{1} h^{-q} \mathrm{~d} u}\right]^{r}
$$

where $\tau$ represents the tortuosity (-). By setting $q=1$ and $r=2$, it becomes the well-known Mualem model for unsaturated hydraulic conductivity (Mualem, 1976a), and, finally, $u$ is the dummy variable of integration. In the rescaled case, this function is marginally different and becomes

$$
K_{\mathrm{rc}}\left(S_{c}\right)=\mathrm{S}_{\mathrm{c}}{ }^{\tau}\left[\frac{\int_{\Gamma_{0}}^{\Gamma} h^{-q} \mathrm{~d} x}{\int_{0}^{1} h^{-q} \mathrm{~d} x}\right]^{r}
$$

Note that the only difference between the two stems from the rescaling approach in equation (3). Peters (2014) gives analytical solutions to equation (11) for some special cases, which could be adopted in the framework, too. For maximum flexibility within this FM, it is recommended to implement numerical solutions to equation (11), which can be considered as essentially error free and fast. With regard to the overall modular framework, equation (10) may be replaced by other expressions (e.g., Burdine, 1953; Clapp \& Hornberger, 1978; Gardner, 1958). 
Table 1

Physical Properties of Selected Soils, Concerning the Particle Size Classification

\begin{tabular}{|c|c|c|c|c|c|}
\hline Soil ID/name & $\begin{array}{l}\text { Clay } \\
(\%)\end{array}$ & $\begin{array}{l}\text { Silt } \\
(\%)\end{array}$ & $\begin{array}{c}\text { Sand } \\
(\%)\end{array}$ & $\begin{array}{c}\rho_{B} \\
\left(\mathrm{~g} / \mathrm{cm}^{3}\right)\end{array}$ & $\begin{array}{c}c_{\mathrm{org}} \\
\left(\mathrm{g} / \mathrm{cm}^{3}\right)\end{array}$ \\
\hline \multicolumn{6}{|l|}{ Pachapa $^{a}$} \\
\hline \multicolumn{6}{|l|}{ Rehovot $^{b}$} \\
\hline \multicolumn{6}{|l|}{ Pachepsky SL ${ }^{c}$} \\
\hline SM 6-62 ${ }^{\text {d,** }}$ & 0.08 & 0.83 & 0.09 & 1.38 & 2.4 \\
\hline SM $22-88^{\mathrm{d}, *}$ & 0.13 & 0.77 & 0.10 & 1.22 & 0.01 \\
\hline SM $35-119^{\mathrm{d}, *}$ & 0.07 & 0.84 & 0.09 & 1.52 & 0.0 \\
\hline SM $41-127^{\mathrm{d}, *}$ & 0.21 & 0.76 & 0.03 & 1.35 & 0.0 \\
\hline SM $1005^{\mathrm{e}, *}$ & 0 & 0.01 & 0.99 & 1.60 & nv \\
\hline UNSODA $2571^{\mathrm{f}}$ & 0.08 & 0.10 & 0.82 & 1.30 & 1.5 \\
\hline UNSODA $4010^{\mathrm{f}}$ & 0.06 & 0.04 & 0.90 & 1.44 & 1.9 \\
\hline UNSODA $4031^{\mathrm{f}}$ & 0.11 & 0.24 & 0.65 & 1.48 & 1.4 \\
\hline UNSODA $4650^{\mathrm{g}, \mathrm{f}}$ & 0.02 & 0.04 & 0.94 & 1.27 & 3.3 \\
\hline Ver P26 C1g g & 0.02 & 0.02 & 0.96 & 1.67 & 0.2 \\
\hline Schelle $\mathrm{S1}^{\mathrm{h}}$ & sand & & & 1.60 & $\mathrm{nv}$ \\
\hline Schelle SL1 ${ }^{\mathrm{h}}$ & loam & & & 1.10 & nv \\
\hline
\end{tabular}

Note. The soils marked with $(*)$ were classified by the German classification system (BGR, 2005; clay $<2 \mu \mathrm{m}, 2 \mu \mathrm{m} \leq$ silt $<63 \mu \mathrm{m}, 63 \mu \mathrm{m} \leq$ sand $<2000 \mu \mathrm{m}$ ), the remaining soils were classified by the FAO system (FAO, 2006; clay $<2 \mu \mathrm{m}, 2 \mu \mathrm{m} \leq$ silt $<50 \mu \mathrm{m}, 50 \mu \mathrm{m} \leq$ sand $<2,000 \mu \mathrm{m}) . \mathrm{nv}=$ no value.

a Jackson et al. (1965). ${ }^{b}$ Mualem (1976b). ${ }^{c}$ Pachepsky et al. (1984).

${ }^{\mathrm{d}}$ Schindler and Müller (2015). ${ }^{\mathrm{e}}$ Schindler and Müller (2010). ${ }^{\mathrm{f}}$ Nemes et al. (2001). ${ }^{\mathrm{g}}$ Vereecken et al. (1989). ${ }^{\mathrm{h}}$ Schelle et al. (2013).

\subsubsection{Hydraulic Noncapillary Conductivity Model Based on the} New Noncapillary Saturation Function

Finally, the noncapillary conductivity is similar to the expression by Peters (2013), who, in turn, based the expression on work by Tokunaga (2009), which we give as

$$
K_{\mathrm{rnc}}\left(S_{\mathrm{nc}}\right)=\left(\frac{\left|h_{0}\right|}{h_{r}}\right)^{-a\left(1-S_{\mathrm{nc}}\right)}
$$

where $h_{r}(\mathrm{~cm})$ is unity, introduced to ensure $K_{r n c}$ is dimensionless, $a(-)$ is the slope of $K_{\text {rnc }}$, and therefore $K_{\text {tot }}$ when the capillary saturation approaches 0 . It could be argued that $K_{\text {rnc }}$ also requires rescaling, similar to the capillary saturation function in equation (3), to ensure $K_{\mathrm{nc}}=0$ at $h_{0}$. However, the effect of this technicality is deemed irrelevant.

\section{Model Testing}

\section{Soil Data}

To test the FM in its ability to describe measured retention and conductivity data, we compiled two sets of data. A first data set containing measurements of 53 samples was obtained from the literature covering mineral soils with a wide range of textures and origins (Mualem, 1976b, data obtained from the SI of Rudiyanto et al., 2015; Schindler \& Müller, 2010; organic soils, Schindler \& Müller, 2015; horticultural substrates, Schindler, 2016, and from the widely used UNSODA, Nemes et al., 2001) and "Vereecken" (Vereecken et al., 1989) databases. Measured data were obtained employing a wide range of measurement techniques. For details the reader is referred to the original sources. A summary of selected samples is given in Table 1. Second, we use two sets of measured retention curves studied by Schelle et al. (2013) in their method comparison: one for a sand (Sand1) and one for a silt loam (Silt Loam 1). We restrict these two data sets to the data obtained by the evaporation experiment (EE) for the slightly moist to medium dry range $\left(h>-10^{3.2} \mathrm{~cm}\right)$, and those obtained by the DP method for the dry range ( $h \leq-10^{3.2} \mathrm{~cm}$; Gee et al. (1992)).

\section{Case Study: Capillary Saturation Function of van Genuchten}

As mentioned above, expressions for saturation functions (in our framework it would be the nonscaled capillary representation of the saturation function) are abundant and can be inserted in equation (3). For a case study, we use the widely used VG saturation function (van Genuchten, 1980) in the modular framework for the capillary part of the retention function in equations (1) and (3). The shape function is given by

$$
\Gamma_{c}(h)=\left[1+(\alpha|h|)^{n}\right]^{-m}
$$

where $\alpha\left(\mathrm{L}^{-1}\right), n(-)$, and $m(-)$ are shape parameters. We constrain $m$ to $m=1-1 / n$, which is beneficial due to the often observed high correlation between $n$ and $m$. In the following, the presented model is named VGM-framework model (VGM-FM).

Figure 5 shows an example of the VGM-FM with details of the capillary and noncapillary parts of the WRC and HCC, using the Mualem integral for the relative capillary conductivity function. The noncapillary parts are calculated based on the newly presented integral method.

Inverse Modeling

Parameters were estimated by minimizing the weighted sum of squared errors given by

$$
\Phi(\boldsymbol{p})=w_{\theta} \sum_{j=1}^{r_{\theta}}\left\langle\theta_{j}-\widehat{\theta}_{j}(\boldsymbol{p})\right\rangle^{2}+w_{K} \sum_{k=1}^{r_{K}}\left\langle\log _{10} K_{k}-\log _{10} \widehat{K}_{k}(\boldsymbol{p})\right\rangle^{2}
$$

where $\boldsymbol{p}$ is the vector of parameters, $\theta_{j}$ are measured and $\widehat{\theta}_{j}(\boldsymbol{p})$ modeled water contents, $K_{k}$ are measured and $\widehat{K}_{k}(\boldsymbol{p})$ modeled conductivities, while $r_{\theta}$ and $r_{k}$ are the lengths of the respective data sets and $w_{\theta}$ and $w_{K}$ are the associated weights, which were calculated for each data class to normalize the range of the 

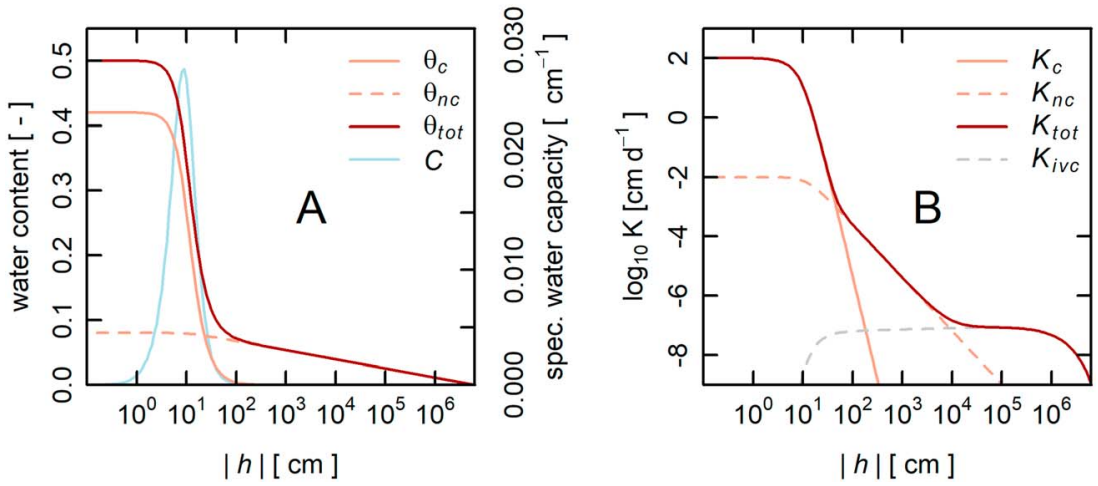

Figure 5. (a) Exemplified retention function of the proposed framework model based on the van Genuchten saturation function for the capillary part in equation (3) and the new model for the noncapillary part in equations (4)-(6) $\left(\theta_{\mathrm{cs}}=0.42, \theta_{\mathrm{ncs}}=0.08, \alpha=0.1 \mathrm{~cm}^{-1}, n=3\right)$. The capillary part drops from a water content value $\theta_{c}$ to 0 . After air entry to the capillary part, the noncapillary water content reduces nearly linearly from $\theta_{\mathrm{nc}}$ to 0 . The total retention function is the summation of the two parts. The total saturated water content is given by adding the saturated water contents of the two parts, that is, $\theta_{s}=\theta_{\mathrm{c}}+\theta_{\mathrm{nc}}$., and $\mathrm{C}$ represents the specific capacity function. (b) Exemplified conductivity function with the modular option of the Mualem model for the capillary conductivity in equation (10) and the noncapillary conductivity in equation (12) $\left(K_{\mathrm{c}}=100 \mathrm{~cm} /\right.$ day, $\tau=0.5, K_{\mathrm{nc}}=10^{-4} \mathrm{~cm} /$ day $)$. The total saturated hydraulic conductivities are given as the sum of the respective parts $K_{\mathrm{tot}}=K_{\mathrm{c}}+K_{\mathrm{nc}}$.

data values between 0 and 1 . We used the differential evolution algorithm (Price et al., 2006) as implemented in the R-package DEoptim (Mullen et al., 2011; Ardia et al., 2016) and used R 3.4.1 (R Core Team, 2017) for the calculations. The goodness of fit was calculated using the root-mean-square weighted error, RMSEw. Parameter estimation was done with the soil physics and soil hydrology R-package version 0.9.18309, and the back bone of the model is available from the SI, implemented as R and Matlab scripts.

\section{Results and Discussion}

\subsection{Model Testing on Measured Data}

Figure 6 shows the measured and VGM-FM model predicted WRC and HCC data of 14 selected samples from diverse literature sources covering a wide range in textures (texture fraction ranges: sand 0.03-0.96, silt 0.09-84, and clay 0.0-0.21). Figure 6 also shows that a water content of 0 could be modelled in all cases. The corresponding estimated parameter values are given in Table 2. Results were obtained by inverse modeling adopting a VG saturation function. Visibly, the VGM-FM model describes the measured data very well, corroborated by the very low RMSEw, $\mathrm{K}$ and $\mathrm{RMSEw}_{, \ominus}$ values with means of $0.02(-)$ and $0.03\left[\log _{10}(\mathrm{~cm} / \mathrm{day})\right]$, respectively (Table 2 ).

In all cases, the structural shape of the measurements was captured very well by the VGM-FM. In particular, our approach overcomes one typical deficiency of the VG saturation function. While the curvatures of the VG model are nearly symmetric on a semilog plot, measured WRC data frequently are not. Often more distinct air entries are observed before the steep slopes in the medium moisture range are attained, which is often followed by smooth transitions toward the drier end. The measured data of the samples Pachapa, UNSODA 2571, SM 41-127, and SM 22-88 in Figure 6 illustrate this phenomenon very clearly.

Measured HCC at pressure heads $<-10^{3} \mathrm{~cm}$ are not as common, so that during past model development and calibration, a bias toward the wetter range may be expected by predominantly considering data in the wetter range. To overcome this, we specifically included samples with measured HCC data from pressure heads of down to $-10^{5} \mathrm{~cm}$. At those pressure heads, the capillary bundle model is modeled as a straight line on the $\log _{10}-\log _{10}$ scale. The examples of the data sets Rehovot, SM 1005, and UNSODA 4010 in Figure 6, make it clear that a change in slope occurs (often between -100 and $-1,000 \mathrm{~cm}$ ), which requires additional model flexibility. Clearly, this model flexibility is achieved using the VGM-FM. It has to be noted that this is possible by introducing only one additional parameter, in comparison to the classical VGM model, and obeys the requirement of model parsimony. 

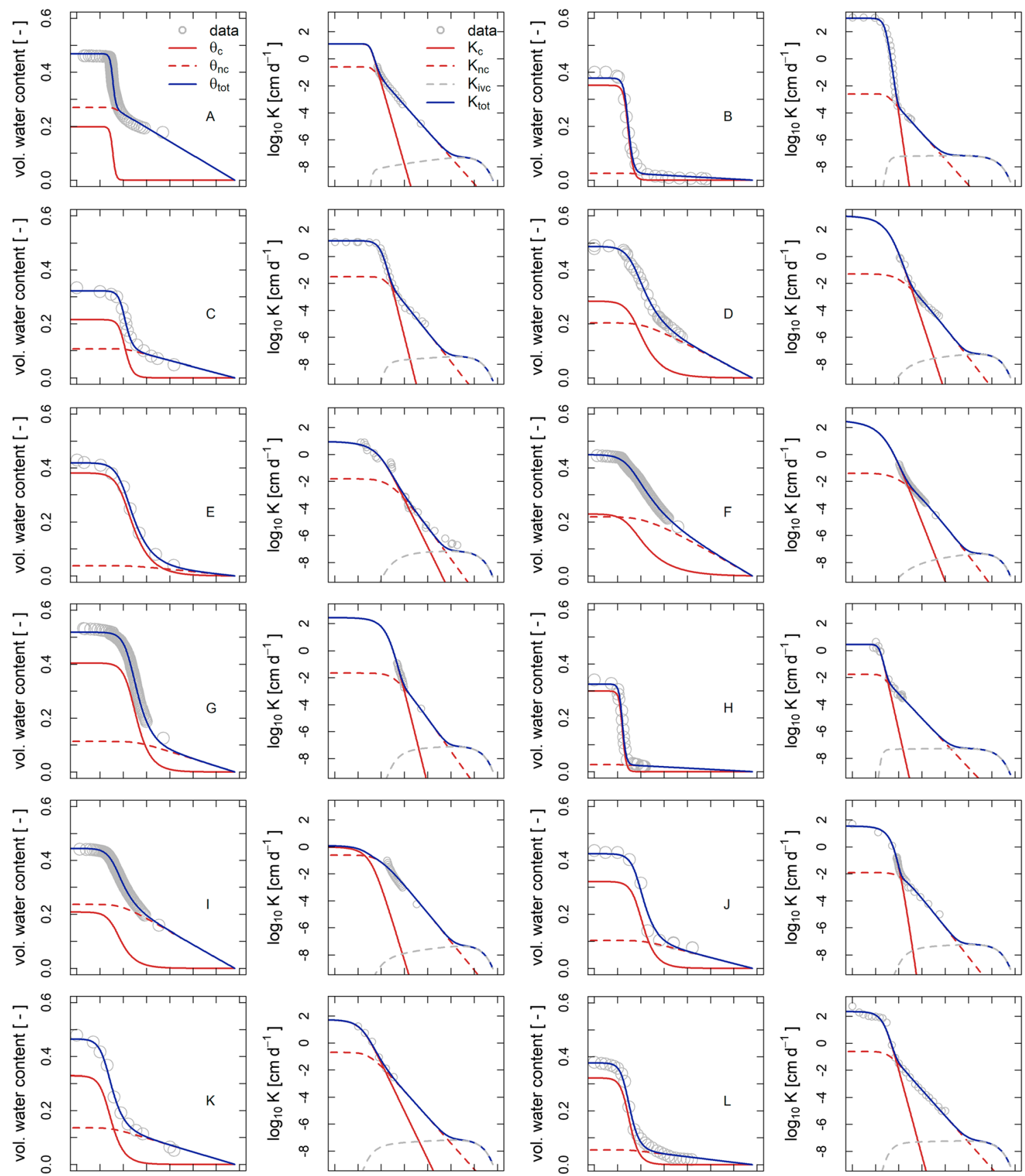

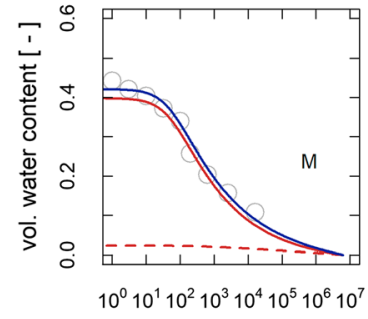

$|\mathrm{h}|[\mathrm{cm}]$

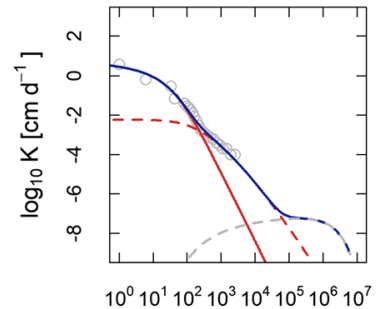

$|h|[\mathrm{cm}]$

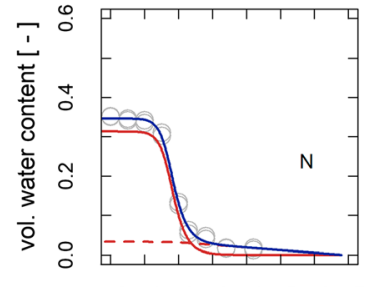

$10^{0} 10^{1} 10^{2} 10^{3} 10^{4} 10^{5} 10^{6} 10^{7}$

$|h|[\mathrm{cm}]$

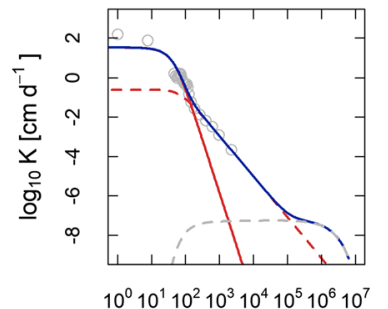

$|h|[\mathrm{cm}]$

Figure 6. Parameterization for 14 different soils (the modular components are described in the text. (a) TS2, (b) Rehovot, (c) Pachapa, (d) SM 6-62, (e) Pachepsky, (f) SM 35-119, (g) SM 22-88, (h) SM 1005, (i) SM 41-127, (j) UNSODA 4010, (k) UNSODA 2571, (l) UNSODA 4650, (m) UNSODA 4031, and (n) VerP26-C1g. In each example the water retention functions reach a water content of $0(-)$ at $\mathrm{pF}=6.8$. Examples of fitting the sample soils replacing the saturation function with the two parametric expression of Kosugi (1996), and the Fredlund-Xing model (Fredlund and Xing (1994), are shown in the supporting information). 
Table 2

Estimated VGM-FM Parameters Through Minimization of Equation (14) and the Goodness of Fit Quantified by the Root-Mean-Square Weighted Error for the Two Data Types (Model Parameters and Weighting Scheme Are Explained in the Text).

\begin{tabular}{|c|c|c|c|c|c|c|c|c|c|}
\hline Soil ID/name & $\theta_{\text {ncs }}(-)$ & $\theta_{\mathrm{cs}}(-)$ & $\alpha\left(\mathrm{cm}^{-1}\right)$ & $n(-)$ & $\log _{10} K_{\mathrm{sc}}\left(\mathrm{cm} /\right.$ day $\left.^{\mathrm{a}}\right)$ & $\tau(-)$ & $\log _{10} K_{\text {snc }}\left(\mathrm{cm} /\right.$ day $\left.^{\mathrm{a}}\right)$ & $\mathrm{RMSE} w_{\theta}(-)$ & $\operatorname{RMSE}_{K}\left(\mathrm{~cm} /\right.$ day $\left.^{\mathrm{a}}\right)$ \\
\hline TS2 & 0.27 & 0.20 & 0.028 & 7.000 & 1.01 & -1.3 & -0.6 & 0.034 & 0.014 \\
\hline Pachapa ${ }^{b}$ & 0.108 & 0.212 & 0.010 & 3.23 & 1.16 & 0.18 & -2.73 & 0.026 & 0.024 \\
\hline Rehovot $^{b}$ & 0.023 & 0.361 & 0.039 & 4.13 & 3.41 & 1.32 & -6.05 & 0.033 & 0.053 \\
\hline Pachepsky SL ${ }^{c}$ & 0.033 & 0.382 & 0.008 & 1.73 & 0.94 & 0.30 & -2.90 & 0.024 & 0.079 \\
\hline SM $22-88^{\mathrm{d}}$ & 0.112 & 0.295 & 0.005 & 1.95 & 2.47 & 3.22 & -4.20 & 0.015 & 0.023 \\
\hline SM $35-119^{\mathrm{d}}$ & 0.196 & 0.058 & 0.032 & 1.37 & 2.68 & 4.04 & -4.19 & 0.011 & 0.008 \\
\hline SM $41-127^{d}$ & 0.230 & 0.215 & 0.025 & 1.84 & 3.19 & 2.18 & -4.21 & 0.007 & 0.004 \\
\hline SM 6-62 & 0.191 & 0.298 & 0.022 & 1.58 & 3.18 & 3.55 & -4.57 & 0.016 & 0.028 \\
\hline SM $1005^{\mathrm{e}}$ & 0.026 & 0.300 & 0.064 & 5.92 & 0.45 & -0.87 & -2.27 & 0.025 & 0.033 \\
\hline UNSODA $2571^{\mathrm{f}}$ & 0.128 & 0.341 & 0.054 & 2.04 & 1.82 & -0.40 & -2.58 & 0.021 & 0.026 \\
\hline UNSODA $4010^{\mathrm{f}}$ & 0.122 & 0.308 & 0.011 & 2.97 & 1.21 & 7.22 & -3.08 & 0.045 & 0.027 \\
\hline UNSDOA $4031^{\mathrm{f}}$ & 0.070 & 0.354 & 0.023 & 1.30 & 0.79 & 1.61 & -2.90 & 0.040 & 0.035 \\
\hline UNSODA $4650^{\mathrm{f}}$ & 0.111 & 0.334 & 0.020 & 2.04 & 1.80 & 0.95 & -2.83 & 0.026 & 0.026 \\
\hline Ver P26 C1g & 0.027 & 0.324 & 0.022 & 2.28 & 1.73 & 0.20 & -2.41 & 0.034 & 0.034 \\
\hline
\end{tabular}

Note. VGM-FM = van Genuchten-Mualem framework model; RMSE = root-mean-square error.

${ }^{\mathrm{a}}$ To be fully consistent with the $\log _{10}$ transformation, the units are $\log 10\left(\mathrm{~cm} /\right.$ day), too. ${ }^{\mathrm{b}}$ Mualem (1976b). ${ }^{\mathrm{c}}$ Pachepsky et al. (1984). ${ }^{\mathrm{d}}$ Schindler and Müller (2015). $\quad{ }^{\mathrm{e}}$ Schindler and Müller (2010). ${ }^{\mathrm{f}}$ Nemes et al. (2001). ${ }^{\mathrm{g}}$ Vereecken et al. (1989).

In earlier studies, it could be shown that the partitioning of the full SHP into noncapillary and capillary parts, may, in comparison to the traditional VGM model, lead to more positive values for $\tau$ (Weber et al., 2017a, 2017b), which is physically plausible (Peters et al., 2011). We note that with the VGM-FM, 11 out of the 14 presented samples were parameterized with $\tau>0$ (Table 2).

\subsection{Prediction of the Dry Range in the Retention Curve}

Since measurements of water retention in the dry range are laborious, the ability of a model to predict the water contents in this range is of great interest. Figure 7 presents such a case. It shows measured retention curves for two samples with different textural properties, one sand sample (Figure 7, left) and one silty loam (Figure 7, right) from Schelle et al. (2013). The black circles represent data obtained from evaluation of EE, and the gray diamonds are DP data.

Only the data from the EE were used to estimate the VGM-FM model parameters. In both cases the model inversion of the observational data leads to small RMSEw values between modeled and measured retention
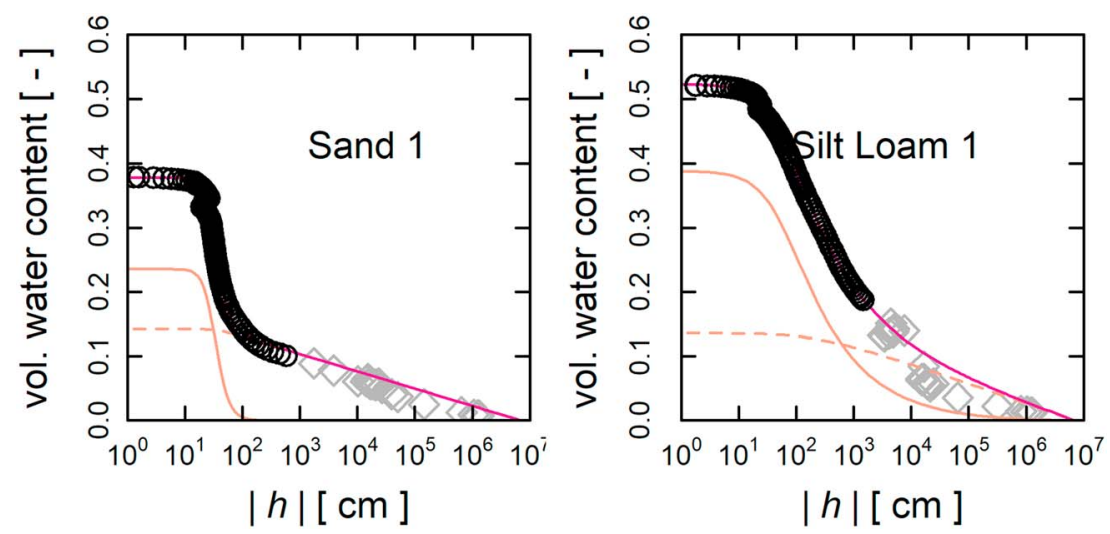

Figure 7. Model prediction of observed data obtained by the dew point method on the dry end of the water retention curve (gray diamonds; pressure heads $>10^{3.2} \mathrm{~cm}$; Schelle et al., 2013). The model prediction is based on the inversion of the data at pressure heads $<10^{3.2}$, only (black circles). For the capillary parts components, the van Genuchten saturation model was used, and for the noncapillary parts, the new modeling framework was employed. The names of the samples correspond to the names in the original source. 
Table 3

Estimated VGM-FM Based on Model Calibration Using Only Data at Pressure Heads below $p F 3.2$

\begin{tabular}{lccccc}
\hline Soil ID/name & $\theta_{\text {snc }}(-)$ & $\theta_{\text {sc }}(-)$ & $\alpha\left(\mathrm{cm}^{-1}\right)$ & $n(-)$ & $\operatorname{RMSE}_{\theta}(-)$ \\
\hline Schelle S1 $^{\mathrm{a}}$ & 0.144 & 0.234 & 0.031 & 4.4 & 0.028 \\
Schelle SL1 $^{\mathrm{a}}$ & 0.101 & 0.427 & 0.021 & 1.4 & 0.01
\end{tabular}

Note. VGM-FM = van Genuchten-Mualem framework model.

${ }^{\mathrm{a}}$ Schelle et al. (2013). curves (Table 3). For Sand1 the prediction of the DP data is very good. It shows no error in the slope. This can be attributed to fixing the WRC to a moisture content of 0 at a pressure head of $h=-10^{6.8} \mathrm{~cm}$; thus, the prediction of the WRC at pressure heads $h<-10^{3.2} \mathrm{~cm}$ can be seen as an interpolation, rather than an extrapolation, and so can be expected to predict the observed values better. The results shown in Figure 7 (right) indicate a reasonable prediction of the DP data for the Silt Loam 1 data; however, it is not as good as for the Sand1 sample. This can be explained by the fact that important information on the shape of the curve is actually missing, when the DP data are not included in the objective function. Examples are the Pachepsky SL and UNSODA 2571 samples, where a wider range is included and a suitable model description is achieved. The resulting VGM-FM model parameters are listed in Table 3.

In summary, by introducing a fix point at which the moisture content is 0 , the prediction of SHP in the dry range is possible, provided that sufficient data are available. An in-depth discussion about the minimum data set for robust estimation of SHP model parameters is beyond the scope of this work.

\section{Summary and Outlook}

As Assouline and Or (2013) pointed out, the reliance on WRC for an inference of the HCC requires improved conceptual models of capillary and viscous interactions within realistic pore spaces. Although we are still far away from a mechanistic-based upscaling of all relevant processes from the pore scale, we think that our model framework introduces an empirical, yet, physically more complete and thus improved model for the description of the effective SHP toward the dry end. The modular framework facilitates a complete description along the entire moisture range. We could show that even in the absence of measured data, the WRC in the dry range was described with reasonable accuracy. The here presented model for the noncapillary saturation function introduces no extra parameter as compared to the traditional retention curve models and can be directly derived from any given expression of the capillary saturation function. For the tested capillary saturation function of van Genuchten (1980), we showed in this paper that we obtained very good modeling results for a variety of soils. Other prominent and widely used capillary saturation functions have been formulated by Fredlund and Xing (1994) and Kosugi (1996), but in principle, any (bounded) continuous statistical distribution can be used. Also, multimodal expressions for $S_{\mathrm{c}}(h)$ can be used.

With respect to the HCC, the modular FM is physically more complete than the traditional models by accounting for capillary, noncapillary, and isothermal vapor flow. The composite conductivity curve requires only one additional model parameter $\left(K_{\mathrm{snc}}\right)$. There is strong evidence that the inclusion of a noncapillary conductivity component is required in numerical simulations under evaporative conditions, when the system state reaches relatively dry conditions. The deficiencies in the capillary bundle model based estimation of the HCC near saturation and the lack of a proper representation of hysteresis in the WRC have not been explicitly discussed in this framework. However, it appears straightforward to adopt the approaches presented by Iden et al. (2015) for the HCC and Rudiyanto et al. (2015) for the WRC, respectively.

The traditional functions are implicitly contained in our FM by setting the modular noncapillary components to 0 and directly using $\Gamma_{\mathrm{c}}(h)$ instead of the rescaled $S_{\text {cap }}(h)$. For example, the VGM (van Genuchten, 1980; Mualem, 1976a), the Brutsaert-Gardner (Brutsaert, 1966; Gardner, 1958), Hutson and Cass-Burdine (Burdine, 1953; Hutson \& Cass, 1987), and Brooks and Corey-Burdine (Brooks \& Corey, 1966) models with their respective mathematical representations can be seen as nested models within the modular framework. The framework can be easily incorporated into existing numerical simulation software (e.g., Hydrus-1D, Šimůnek et al., 2016; Expert-N, Priesack, 2006; DAISY, Hansen et al., 2012; SOIL-SOILN, Jansson, 1999; LEACHN, Hutson \& Wagenet, 1992; and NOAH-MP GECROS, Ingwersen et al., 2018). Implementing the novel framework into existing codes would increase flexibility, benefitting research and model application, and finally, it can lead to more accurate simulations. 
It remains an open question to what extent these more structurally detailed models are beneficial in improving simulations of water fluxes in the soil-plant-atmosphere continuum. Since the differences between the traditional parameterizations and the models are particularly large in the hydraulic conductivity function in the medium to dry region, we expect that plant water uptake and bare soil evaporation under semiarid and arid conditions may be greatly affected. However, further studies are required to test this hypothesis.

\section{Appendix A: Material and Methods of the EE}

In the following, the material and methods which were used to obtain the measured data for Figure 1 are explained.

The tailing sand soil used for the EEs was collected in June 2015 from a constructed fen in Northern Alberta (Ketcheson et al., 2016, 2017), stored in buckets and transported to the laboratory. Subsequently, two 250$\mathrm{cm}^{3}$ cylinders $(5 \mathrm{~cm}$ i.h., $8 \mathrm{~cm}$ i.d.) were packed, saturated with de-aired water, and mounted on a HYPROP (v1; UMS GmbH) device open to the atmosphere on the upper boundary. The EE was conducted in a room at a constant temperature of $20^{\circ} \mathrm{C}$ and the evaporation rate determined from the weight loss between two measurement times. From knowledge of the oven dry soil weight, determined at $105{ }^{\circ} \mathrm{C}$ until a constant weight over 1 day was achieved, the water contents of the soil at each time step was determined. From the two tensiometers readings, installed at 1.25 and $3.75 \mathrm{~cm}$, an average pressure head and the gradient for the calculation of the unsaturated hydraulic conductivity at the midpoint of the sample was determined. The pressure head-water content relationship (WRC) and the pressure head-hydraulic conductivity relationship (HCC) are given in Figure 1. More details on the measurement technique can be found in Schindler et al. (2010).

Table B1

Tortuosity Models Implemented in the Functions of the Supporting Information

\begin{tabular}{|c|c|c|}
\hline$\xi$-model & Reference & Model code \\
\hline$\theta_{a}^{10 / 3} / \phi^{2}$ & Millington and Quirk (1961) & $\begin{array}{l}\text { MQ61 } \\
\quad(\text { standard })\end{array}$ \\
\hline$\theta_{a}^{2} / \phi^{2 / 3}$ & Millington and Quirk (1960) & MQ60 \\
\hline $0.66 \theta_{a}\left(\frac{\theta_{a}}{\phi}\right)^{\frac{12-m}{3}}$ & Moldrup et al. (1997) & PMQ \\
\hline$\phi^{2}\left(\frac{\theta_{a}}{\phi}\right)^{X}$, with & & \\
\hline$X=\frac{\log _{10}\left(\frac{2^{*} \theta_{100}^{3}+0.04 \theta^{*} \theta_{100}}{\phi^{2}}\right)}{\log _{10}\left(\frac{\theta_{100}}{\phi}\right)}$ & Moldrup et al. (2004) & TPM \\
\hline$\phi^{2}\left(\frac{\theta_{a}}{\phi}\right)^{X}$, with & & \\
\hline$X=2+0.25 \frac{\log _{10}\left(\theta_{100}\right)}{\log _{10}\left(\frac{\theta_{100}}{\phi}\right)}$ & Moldrup et al. (2005) & TPEM \\
\hline$\theta_{a}^{2.51} / \phi^{2}$ & Xu et al. (1992) & $\mathrm{Xu}$ \\
\hline $1 e^{-6} \theta_{a}^{3.36}$ & Grable and Siemer (1968) & GS \\
\hline $0.66\left(\theta_{a}-\phi_{i m}\right)$ & Call (1957) & $\mathrm{C}$ \\
\hline$\theta_{a}^{5 / 3}$ & Lai et al. (1976) & $\mathrm{L}$ \\
\hline $0.66 \theta_{a}$ & Penman (1940) & $P$ \\
\hline$\theta_{a}^{2}$ & Buckingham (1904) & B \\
\hline
\end{tabular}

\section{Appendix B: Models for the Isothermal Vapor Conductivity}

Under isothermal and isobaric conditions, water vapor conductivity, $K_{\mathrm{ivc}}$ (LT-1), only depends on the vapor diffusivity, $D\left(\mathrm{~L}^{2} / \mathrm{T}\right.$; e.g., Saito et al., 2006).

$$
K_{\mathrm{ivc}}=\frac{\rho_{\mathrm{sv}}}{\rho_{\mathrm{w}}} D \frac{M_{\mathrm{w}} \mathrm{g}}{R T} a_{\mathrm{w}}
$$

where $\rho_{\mathrm{sv}}\left(\mathrm{M} / \mathrm{L}^{3}\right)$ is the saturated vapor density, $\rho_{\mathrm{w}}\left(\mathrm{M} / \mathrm{L}^{3}\right)$ is the density of liquid water, $M_{w}(\mathrm{MN}-1)$ is the molecular weight of water, $g\left(\mathrm{~L} / \mathrm{T}^{2}\right)$ is the gravitational acceleration, $R(\mathrm{M} \mathrm{L} 2 /(\mathrm{T} 2 \mathrm{~N} \theta))$ is the universal gas constant, $T(\theta)$ the absolute temperature, $a_{\mathrm{w}}$ is water activity ( - ), calculated from the Kelvin equation, $a_{\mathrm{w}}=\exp \left(-\frac{h M g}{R T}\right)$, as used in Riedel and Weber (2016), with $h$ (L) as pressure head. The vapor diffusivity is determined by relating the diffusivity of water vapor in air, $D_{a}\left(\mathrm{~L}^{2} / \mathrm{T}^{1}\right)$ to that in an unsaturated soil, which is achieved by accounting for the pressure head dependent volumetric air content, $\theta_{a}(h)$ given by

$$
D=\xi D_{a}
$$

$D$ also depends on the substrate's tortuosity, $\xi(-)$, for which some empirical models are given in Table B1 ( $\xi$ must not be confused with the "tortuosity" parameter of the Mualem's integral)

Finally,

$$
\theta_{a}(h)=\phi-\theta(h)
$$

where $\phi\left(\mathrm{L}^{3} / \mathrm{L}^{3}\right)$ is the soil porosity, which can, for the sake of simplicity, be set equal to $\theta_{s}$. 
The expressions for $D_{a}$ and $\rho_{\mathrm{sv}}$ can be found in Saito et al. (2006).

For the sake of readability we dropped the $(h)$ notation from $\theta_{a}(h), \theta_{100}$, is the air content at a pressure head of $100 \mathrm{~cm}, \phi_{\mathrm{im}}$ is the immobile pore space, which we set to $\theta_{r}$, but ensure the expression $\theta_{a}-\phi_{\mathrm{im}}$ remains positive. Since organic soils are receiving increasing attention (Weber et al. 2018, Gerling et al. 2019), we would like to point out the tortuosity model for gas diffusion of Caron and Nkongolo (2004) but do not include it here.

\section{Appendix C: On the Relative Steepness of the Saturation Functions}

For simplicity, the following derivation is based on the modulus of the pressure head, $|h|$, also known as the soil moisture tension. Both $S_{\mathrm{c}}$ and $S_{\mathrm{nc}}$ have accordingly been redefined as functions of $|h|$. Assuming that both $S_{\mathrm{c}}(|h|)$ and $S_{\mathrm{nc}}(|h|)$, respectively range from unity (at $|h|=0$ and $\left.|h|=\left|h_{\epsilon}\right|\right)$ to 0 (at $\left.|h|=\left|h_{0}\right|\right)$, it follows that.

$$
S_{\mathrm{c}} \leq S_{\mathrm{nc}} \text { at }|h|=\left|h_{\epsilon}\right|
$$

and $S_{\mathrm{c}}(|h|) \leq S_{\mathrm{nc}}(|h|)$ is guaranteed to hold as long as

$$
\frac{\mathrm{d} S_{c}}{\mathrm{~d}|h|} \leq \frac{\mathrm{d} S_{\mathrm{nc}}}{\mathrm{d}|h|}
$$

on the interval $\left[\left|h_{\epsilon}\right|,|h|\right]$. Taking the derivative of equation (7) (combined with equation (6)) yields

$$
\frac{\mathrm{d} S_{\mathrm{nc}}}{\mathrm{d}|h|}=\left(S_{\mathrm{c}}-1\right) /\left(|h| S_{\mathrm{nc}, f}\right)
$$

where, by definition

$$
S_{\mathrm{nc}, f}=-\int_{\left|h_{\varepsilon}\right|}^{\left|h_{0}\right|} \frac{S_{\mathrm{c}}\left(\left|h^{\prime}\right|\right)-1}{\left|h^{\prime}\right|} \mathrm{d}\left|h^{\prime}\right|
$$

Acknowledgments As all authors have a strong link to the TU 'Brunswick model', we suggest Brunswick model as a name for this framework model. This work was funded by the Collaborative Research Center 1253 CAMPOS (Project 7: Stochastic Modeling Framework), funded by the German Research Foundation (DFG, Grant Agreement SFB 1253/1 2017). The measured data are directly available from the cited publications. The data of TS are contained in the soil physics and soil hydrology R-package from the SI. We wish to express our special thanks to Andre Peters, who gave us the inspiration to this framework with his encompassing Water Resources Research manuscript "Simple consistent models for water retention and hydraulic conductivity in the complete moisture range." We also thank Robert Rauch, Lauritz Streck, Sebastian Gayler, and Frederik Schrader for fruitful and instructive discussions and Greenlaw for proofreading. The flowchart of the framework presented in Figure 2 is available in high-quality format from the supporting information. We thank Xavier Sanchez-Vila and the anonymous reviewers for their work.
Note that $S_{\mathrm{nc}, f}$ equals the area above the retention curve in $p F$ space (bounded by $\left.S_{c}=1\right)$ divided by $\log _{10}(e)$. Inserting equation (C3) into equation (C2) finally gives:

$$
\frac{\mathrm{d} S_{c}}{\mathrm{~d}|h|} \leq\left(S_{\mathrm{c}}-1\right) /\left(|h| S_{\mathrm{nc}, f}\right)
$$

Equation (C5) can be evaluated for specific retention models. Inserting, for example, the VG model (equation (13)), $\Gamma_{\mathrm{c}}(|h|)=\left(1+(a|h|)^{n}\right)^{\frac{1}{n}-1}$, into equation (C5) (through equation (3)) yields

$$
\left(1+(a|h|)^{n}\right)^{\frac{1}{n}-1}-\left(S_{\mathrm{nc} . f}(n-1)+1\right)(a|h|)^{n}-1 \leq 0
$$

Evaluation at, for example, $a|h|=1$, yields

$$
\frac{1}{n-1}\left(2^{2-\frac{1}{n}}-2\right) \leq S_{\mathrm{nc}, f}
$$

In general, $n \geq 1.1$ and $S_{\mathrm{nc}, f}>3$, so that equation (C7) (and hence equation (C5)) will hold and the new model can safely be applied.

\section{References}

Ardia, D., Mullen, K. M., Peterson, B. G., Ulrich, J. (2016). ‘DEoptim': Differential evolution in 'R'. version 2.2-4.

Asseng, S., Ewert, F., Rosenzweig, C., Jones, J. W., Hatfield, J. L., Ruane, A. C., et al. (2013). Uncertainties in simulating wheat yields under climate change. Nature Climate Change, 3(9), 827-832. https://doi.org/10.1038/nclimate1916

Assouline, S., \& Or, D. (2013). Conceptual and parametric representation of soil hydraulic properties: A review. Vadose Zone Journal, 12(4). https://doi.org/10.2136/vzj2013.07.0121

Beckie, R. (2006). Fundamental hydrologic equations. Encyclopedia of Hydrological Sciences., 1, 5. https://doi.org/10.1002/0470848944. hsa004 
BGR (Bundesanstalt für Geowissenschaften und Rohstoffe) [Ed.] (2005). Bodenkundliche Kartieranleitung - 5., verb. und erw. Aufl. Stuttgart. Schweizerbart.

Bogena, H., Borg, E., Brauer, A., Dietrich, P., Hajnsek, I., Heinrich, I., et al. (2016). TERENO: German network of terrestrial environmental observatories. In Journal of large-scale research facilities, (Vol. 2, p. A52). https://doi.org/10.17815/jlsrf-2-98

Bouma, J. (2016). Hydropedology and the societal challenge of realizing the 2015 United Nations sustainable development goals. Vadose Zone Journal, 15(12). https://doi.org/10.2136/vzj2016.09.0080

Brooks, H., \& Corey, A. T. (1966). Properties of porous media affecting fluid flow. Proceedings of the American Society of Civil Engineers, 92 , 61-88.

Brooks, R. H., \& Corey, A. T. (1964). Hydraulic Properties of Porous Media, Hydrology Papers No 3, Colorado State University, Fort Collings, Colorado.

Brutsaert, W. (1966). Probability laws for pore size distributions. Soil Science, 101(2), 85-92. https://doi.org/10.1097/00010694-19660200000002

Buckingham, E. (1904). Contributions to our knowledge of the aeration status of soils. Bulletin 25. USDA Bureau of Soils, Washington, DC. Burdine, N. T. (1953). Relative permeability calculations from pore size distribution data. Transactions of AIME, $198,71$.

Campbell, G. S., \& Shiozawa, S. (1992). Prediction of hydraulic properties of soils using particle-size distribution and bulk density data. In M. T. van Genuchten, F. J. Leij, \& L. J. Lund (Eds.), Proceedings of the international workshop on indirect methods for estimating the hydraulic properties of unsaturated soils, (pp. 317-328). Riverside: University of California.

Caron, J., \& Nkongolo, N. V. (2004). Assessing gas diffusion coefficients in growing media growing media from in situ water flow and storage measurements. Vadose Zone Journal, 3(1), 300-311, 2004. https://doi.org/10.2136/vzj2004.3000

Carsel, R. F., \& Parrish, R. S. (1988). Developing joint probability distributions of soil water retention characteristics. Water Resources Research, 24(5), 755-769. https://doi.org/10.1029/WR024i005p00755

Chen, L., Li, Y., Chen, F., Barr, A., Barlage, M., \& Wan, B. (2016). The incorporation of an organic soil layer in the Noah-MP land surface model and its evaluation over a boreal aspen forest. Atmospheric Chemistry and Physics, 16(13), 8375-8387. https://doi.org/10.5194/acp16-8375-2016. Schaap

Clapp, R. B., \& Hornberger, G. M. (1978). Empirical equations for some soil hydraulic properties. Water Resources Research, 14(4), 601-604. https://doi.org/10.1029/WR014i004p00601

Coppola, A. (2000). Unimodal and bimodal descriptions of hydraulic properties for aggregated soils. Soil Science Society of America Journal, $64,125-1262$.

Cornelis, W. M., Khlosi, M., Hartmann, R., van Meirvenne, M., \& de Vos, B. (2005). Comparison of unimodal analytical expressions for the soil-water retention curve. Soil Science Society of America Journal, 69(6), 1902-1911. https://doi.org/10.2136/sssaj2004.0238

Diamantopoulos, E., \& Durner, W. (2012). Dynamic nonequilibrium of water flow in porous media: A review. Vadose Zone Journal, 11(3). https://doi.org/a10.2136/vzj2011.0197

Diamantopoulos, E., \& Durner, W. (2013). Physically-based model of soil hydraulic properties accounting for variable contact angle and its effect on hysteresis. Advances in Water Resources, 59, 169-180. https://doi.org/10.1016/j.advwatres.2013.06.005

Diamantopoulos, E., \& Durner, W. (2015). Closed-form model for hydraulic properties based on angular pores with lognormal size distribution. Vadose Zone Journal, 14(2). https://doi.org/10.2136/vzj2014.07.0096

Diamantopoulos, E., Iden, S. C., \& Durner, W. (2012). Inverse modeling of dynamic non-equilibrium in water flow with an effective approach. Water Resources Research, 48, W03503. https://doi.org/10.1029/2011WR010717

Diamantopoulos, S., Šimůnek, J., Oberdörster, C., Hammel, K., Jene, B., Schröder, T., \& Harter, T. (2017). Assessing the potential exposure of groundwater to pesticides: A model comparison. Vadose Zone Journal, 16(11). https://doi.org/10.2136/vzj2017.04.0070

Durner, W. (1992). Predicting the unsaturated hydraulic conductivity using multi-porosity water retention curves. In R. van Genuchten, et al. (Eds.), Indirect methods for estimating the hydraulic properties of unsaturated soils, (pp. 185-202). Riverside: University of California.

Durner, W. (1994). Hydraulic conductivity estimation for soils with heterogeneous pore structure. Water Resources Research, 30(2), 211-223. https://doi.org/10.1029/93WR02676

Durner, W., \& Flühler, H. (2006). Chapter 74: Soil hydraulic properties. In M. G. Anderson, \& J. J. McDonnell (Eds.), Encyclopedia of hydrological sciences, chapter 74 (pp. 1103-1120). John Wiley \& Sons. https://doi.org/10.1002/0470848944.hsa077c.)

Fayer, M. J., \& Simmons, C. S. (1995). Modified soil water retention functions for all matric suctions. Water Resources Research, 31(5), 1233-1238. https://doi.org/10.1029/95WR00173

Field, J. P., Breshears, D. D., Law, D. J., Villegas, J. C., Lopez-Hoffman, L., Brooks, P. D., et al. (2015). Critical zone services: Expanding context, constraints, and currency beyond ecosystem services. Vadose Zone Journal, 14(1). https://doi.org/10.2136/vzj2014.10.0142

Fredlund, D. G., \& Xing, A. (1994). Equations for the soil-water characteristic curve. Canadian Geotechnical Journal, 31(4), 521-532. https://doi.org/10.1139/t94-061

Gardner, W. R. (1958). Some steady state solutions of the unsaturated moisture flow equation with application to evaporation from a water table. Soil Science, 85(4), 228-232. https://doi.org/10.1097/00010694-195804000-00006

Gee, G. W., Campbell, M. D., Campbell, G. S., \& Campbell, J. H. (1992). Rapid measurement of low soil water potentials using a water activity meter. Soil Science Society of America Journal, 56(4), 1068-1070. https://doi.org/10.2136/sssaj1992.03615995005600040010x

Gerling, L., Weber, T. K. D., Reineke, D., Durner, W., Martin, S., \& Weber, S. (2019). Eddy covariance based surface-atmosphere exchange and crop coefficient determination in a mountainous peatland. Ecohydrology, 12(1), e2047. https://doi.org/10.1002/eco.2047

Grable, A. R., \& Siemer, E. G. (1968). Effects of bulk density, aggregate size, and soil water suction on oxygen diffusion, redox potentials, and elongation of corn root. Soil Science Society of America Proceedings, 32(2), 180-186. https://doi.org/10.2136/ sssaj1968.03615995003200020011x

Green, T. R., Ahuja, L. R., \& Benjamin, J. G. (2003). Advances and challenges in predicting agricultural management effects on soil hydraulic properties. Geoderma, 116(1-2), 3-27. https://doi.org/10.1016/S0016-7061(03)00091-0

Guo, L., \& Lin, H. (2016). Critical zone research and observatories: Current status and future perspectives. Vadose Zone Journal, 15, 9. https://doi.org/10.2136/vzj2016.06.0050vzj2016.06.005

Hansen, S., Abrahamsen, P., Petersen, C. T., \& Styczen, M. (2012). Daisy: Model use, calibration, and validation. Transactions of the ASABE, 55(4), 1315-1333.

Hoffmann-Riem, H., van Genuchten, M. T., \& Flühler, H. (1999). General model for the hydraulic conductivity of unsaturated soils. In M. T. van Genuchten, F. J. Leij, \& L. Wu (Eds.), Proceedings of the international workshop on characterization and measurement of the hydraulic properties of unsaturated porous media (pp. 31-42). Riverside: University of California.

Hopmans, J. W., Simunek, J., Romano, N., \& Durner, W. (2002). Chapter 3.6. Simultaneous determination of water transmission and retention properties. In J. H. Dane, \& G. C. Topp (Eds.), Agronomy 9Methods of soil analysis, Part 4, Physical methods. Madison, WI. 
Hutson, J. L., \& Cass, A. (1987). A retentivity function for use in soil-water simulation models. Journal of Soil Science, $38(1), 105-113$. https://doi.org/10.1111/j.1365-2389.1987.tb02128.x

Hutson, J. L., \& Wagenet, R. J. (1992). LEACHM. Leaching Estimation And CHemistry Model: A process based model of water and solute movement, transformations, plant uptake and chemical reactions in unsaturated zone. Version 3. Dep. of Agronomy, Cornell Univ., Ithaca, NY.

Iden, S., \& Durner, W. (2014). Comment on "Simple consistent models for water retention and hydraulic conductivity in the complete moisture range” by A. Peters. Water Resources Research, 50, 7530-7534. https://doi.org/10.1002/2014WR015937

Iden, S. C., \& Durner, W. (2007). Free-form estimation of the unsaturated soil hydraulic properties by inverse modeling using global optimization. Water Resources Research, 43, W07451. https://doi.org/10.1029/2006WR005845

Iden, S. C., Peters, A., \& Durner, W. (2015). Improving prediction of hydraulic conductivity by constraining capillary bundle models to a maximum pore size. Advances in Water Resources, 85, 86-92. https://doi.org/10.1016/j.advwatres.2015.09.005

Ingwersen, J., Högy, P., Wizemann, H.-D., Warrach-Sagi, K., \& Streck, T. (2018). Coupling the land surface model Noah-MP with the generic crop growth model Gecros: Model description, calibration and validation. Agricultural and Forest Meteorology, 262, 322-339. https://doi.org/10.1016/j.agrformet.2018.06.023

Jackson, R. D., Reginato, R. J., \& van Bavel, C. H. M. (1965). Comparison of measured and calculated hydraulic conductivities of unsaturated soils. Water Resources Research, 1(3), 375-380. https://doi.org/10.1029/wr001i003p00375

Jansson, P.-E. (1999). Simulation model for soil water and heat conditions. Description of the SOIL model. Uppsala, Sweden: Swed. Univ. Agric. Sci., Dept. Soil Sci.

Jury, W. A., \& Vaux, H. Jr. (2005). The role of science in solving the world's emerging water problems. Proceedings of the National Academy of Sciences, 102(44), 15,715-15,720.

Ketcheson, S. J., Price, J. S., Carey, S. K., Petrone, R. M., Mendoza, C. A., \& Devito, K. J. (2016). Constructing fen peatlands in post-mining oil sands landscapes: Challenges and opportunities from a hydrological perspective. Earth-Science Reviews, 161(1), 130-139. https://doi. org/10.1016/j.earscirev.2016.08.007

Ketcheson, S. J., Price, J. S., Sutton, O., Sutherland, G., Kessel, E., \& Petrone, R. M. (2017). The hydrological functioning of a constructed fen wetland watershed. Science of the Total Environment, 603-604, 593-605. https://doi.org/10.1016/j.scitotenv.2017.06.101

Khlosi, M., Cornelis, W. M., Douaik, A., van Genuchten, M. T., \& Gabriels, D. (2008). Performance evaluation of models that describe the soil water retention curve between saturation and oven dryness. Vadose Zone Journal, 7(1), 87-96. https://doi.org/10.2136/ vzj2007.0099

Khlosi, M., Cornelis, W. M., Gabriels, D., \& Sin, G. (2006). Simple modification to describe the soil water retention curve between saturation and oven dryness. Water Resources Research, 42, W11501. https://doi.org/10.1029/2005/WR004699

Kirkby, M. J. (2016). Water in the critical zone: Soil, water and life from profile to planet. The Soil, 2(4), 631-645. https://doi.org/10.5194/ soil-2-631-2016

Kool, J. B., \& Parker, J. C. (1987). Development and evaluation of closed-form expressions for hysteretic soil hydraulic properties. Water Resources Research, 23(1), 105-114. https://doi.org/10.1029/WR023i001p00105

Kosugi, K. (1994). Three-parameter lognormal distribution model for the soil water retention. Water Resources Research, 30(4), 891-901. https://doi.org/10.1029/93WR02931

Kosugi, K. (1996). Lognormal distribution model for unsaturated hydraulic properties. Water Resources Research, 32(9), 2697-2703. https:// doi.org/10.1029/96WR01776

Kosugi, K., Hopmans, J. W., \& Dane, J. H. (2002). Parametric models. In J. H. Dane, \& G. C. Topp (Eds.), Methods of soil analysis, (p. 1692). Madison, WI: Soil Science Society of America.

Lai, S. H., Tiedje, J. M., \& Erickson, E. (1976). In situ measurement of gas diffusion coefficient in soils. Soil Science Society of America Journal, 40(1), 3-6. https://doi.org/10.2136/sssaj1976.03615995004000010006x

Lebeau, M., \& Konrad, J.-M. (2010). A new capillary and thin film flow model for predicting the hydraulic conductivity of unsaturated porous media. Water Resources Research, 46, W12554. https://doi.org/10.1029/2010WR009092

Leij, F. J., Russel, W. B., \& Lesch, S. M. (1997). Closed-form expressions for water retention and conductivity data. Ground Water, 35(5), 848-858. https://doi.org/10.1111/j.1745-6584.1997.tb00153.x

Lenhard, R. J., \& Parker, J. C. (1987). A model for hysteretic constitutive relations governing multiphase flow: 2. Permeability-saturation relations. Water Resources Research, 23(12), 2197-2206. https://doi.org/10.1029/WR023i012p02197

Lin, H. (2014). A new worldview of soils. Soil Science Society of America Journal, 78(6), 1831-1844. https://doi.org/10.2136/ sssaj2014.04.0162

Madi, R., de Rooij, G. H., Mielenz, H., \& Mai, J. (2016). Parametric soil water retention models: A critical evaluation of expressions for the full moisture range. Hydrology and Earth System Sciences Discussions, 1-63. https://doi.org/10.5194/hess-2016-168

Mallants, D., Tseng, P. H., Toride, N., Timmerman, A., \& Feyen, a J. (1997). Evaluation of multimodal hydraulic functions in characterizing a heterogeneous field soil. Journal of Hydrology, 195(1-4), 172-199. https://doi.org/10.1016/S0022-1694(96)03251-9

Millington, R. J., \& Quirk, J. M. (1960). Transport in porous media. In F. A. van Beren, et al. (Eds.), Trans. 7th Int. Congr. Soil Sci., Vol. 1, Madison, WI. 14-24 Aug. 1960 (pp. 97-106). Amsterdam: Elsevier.

Millington, R. J., \& Quirk, J. P. (1961). Permeability of porous solids. Trans. Transactions of the Faraday Society, 57, 1200. https://doi.org/ $10.1039 / \mathrm{tf} 9615701200$

Moldrup, P., Olesen, T., Rolston, D. E., \& Yamaguchi, T. (1997). Modeling diffusion and reaction in soils: VII. Predicting gas and ion diffusivity in undisturbed and sieved soils. Soil Science, 162(9), 632-640. https://doi.org/10.1097/00010694-199709000-00004

Moldrup, P., Olesen, T., Yoshikawa, S., Komatsu, T., McDonald, A. M., \& Rolston, D. E. (2005). Predictive-descriptive models for gas and solute diffusion coefficients in variably saturated porous media coupled to pore-size distribution: III. Inactive pore space interpretations of gas diffusivity. Soil Science, 170(11), 867-880. https://doi.org/10.1097/01.ss.0000196770.45951.06

Moldrup, P., Olesen, T., Yoshikawa, S., Komatsu, T., \& Rolston, D. E. (2004). Three-porosity model for predicting the gas diffusion coefficient in undisturbed soil. Soil Science Society of America Journal, 68(3), 750-759. https://doi.org/10.2136/sssaj2004.7500

Mualem, Y. (1976a). A new model for predicting the hydraulic conductivity of unsaturated porous media. Water Resources Research, 12(3), 513-522. https://doi.org/10.1029/WR012i003p00513

Mualem, Y. (1976b). A catalogue of the hydraulic properties of unsaturated soils, Tech. Rep., Technion, Israel Inst. of Technol.

Mualem, Y., \& Dagan, G. (1978). Hydraulic conductivity of soils: Unified approach to the statistical models. Soil Science Society of America Journal, 42(3), 392-395. https://doi.org/10.2136/sssaj1978.03615995004200030003x

Mullen, K. M., Ardia, D., Gil, D., Windover, D., \& Cline, J. (2011). ‘DEoptim’: An R package for global optimization by differential evolution. Journal of Statistical Software, 40(6), 1-26. 
Nassar, I. N., \& Horton, R. (1989). Water transport in unsaturated non-isothermal salty soil: II. Theoretical development. Soil Science Society of America Journal, 53(5), 1330-1337. https://doi.org/10.2136/sssaj1989.03615995005300050005x

Nemes, A., Schaap, M., Leij, F., \& Wösten, J. (2001). Description of the unsaturated soil hydraulic database UNSODA version 2.0. Journal of Hydrology, 251(3-4), 151-162. https://doi.org/10.1016/S0022-1694(01)00465-6

Nimmo, J. R. (1991). Comment on treatment of residual water content in "a consitent set of parametric models for the two-phase-flow of immiscible fluids in the subsurface” by L. Luckner et al. Water Resources Research, 27(4), 661-662. https://doi.org/10.1029/91WR00165

Nimmo, J. R. (2004). Porosity and pore size distribution. In D. Hillel (Ed.), Encyclopedia of soils in the environment, (Vol. 3, pp. 295-303). London: Elsevier.

Noborio, K., McInnes, K. J., \& Heilman, J. L. (1996). Two-dimensional model for water, heat, and solute transport in furrow-irrigated soil: I. theory. Soil Science Society of America Journal, 60(4), 1001-1009. https://doi.org/10.2136/sssaj1996.03615995006000040007x

Othmer, H., Dieckkrüger, B., \& Kutilek, M. (1991). Bimodal porosity and unsaturated hydraulic conductivity. Soil Science, 152(3), 139-150. https://doi.org/10.1097/00010694-199109000-00001

Pachepsky, Y., Scherbakov, R., Varallyay, G., \& Rajkai, K. (1984). On obtaining soil hydraulic conductivity curves from water retention curves [in Russian. Pochvovedenie, 10, 60-72.

Penman, H. L. (1940). Gas and vapour movement through soils I. The diffusion of vapors through porous solids. The Journal of Agricultural Science, 30, 437-462.

Peters, A. (2013). Simple consistent models for water retention and hydraulic conductivity in the complete moisture range. Water Resources Research., 49, 6765-6780. https://doi.org/10.1002/wrcr.20548

Peters, A. (2014). Reply to comment by S. Iden and W. Durner on "Simple consistent models for water retention and hydraulic conductivity in the complete moisture range". Water Resources Research, 50, 7535-7539. https://doi.org/10.1002/2014WR016107

Peters, A., \& Durner, W. (2008). A simple model for describing hydraulic conductivity in unsaturated porous media accounting for film and capillary flow. Water Resources Research, 44, W11417. https://doi.org/10.1029/2008WR007136

Peters, A., Durner, W., \& Wessolek, G. (2011). Consistent parameter constraints for soil hydraulic functions. Advances in Water Resources, 34(10), 1352-1365. https://doi.org/10.1016/j.advwatres.2011.07.006

Price, K. V., Storn, R. M., \& Lampinen, J. A. (2006). Differential evolution-A practical approach to global optimization. Berlin Heidelberg: Springer-Verlag. ISBN 3540209506. https://doi.org/10.1007/3-540-31306-0

Priesack, E. (2006). Expert-N Dokumentation der Modellbibliothek - FAM-Bericht 60. Forschungsver-bund Agrarökosysteme München Erfassung, Prognose und Bewertung nutzungsbedingter Verände-rungen in Agrarökosystemen und deren Umwelt. Hyronimus Buchproduktions GmbH München, Germany (in German).

R Core Team (2017). R: A language and environment for statistical computing. R Foundation for Statistical Computing, Vienna, Austria. URL https://www.R-project.org/

Richards, L. A. (1931). Capillary conduction of liquids through porous mediums. Journal of Applied Physics, 1(5), 318-333.

Richardson, L. F. (1922). Weather prediction by numerical process, (2nd ed.). Cambridge: Cambridge mathematical library. New York, Cambridge University Press.

Riedel, T., \& Weber, T. K. D. (2016). The chemical potential of water in soils and sediments. Soil Science Society of America Journal, 80(1). https://doi.org/10.2136/sssaj2015.02.0085

Romano, N., \& Nasta, P. (2016). How effective is bimodal soil hydraulic characterization? Functional evaluations for predictions of soil water balance. European Journal of Soil Science, 67(4), 523-535. https://doi.org/10.1111/ejss.12354

Ross, P. J., \& Smettem, K. R. J. (1993). Describing soil hydraulic properties with sums of simple functions. Soil Science Society of America Journal, 57(1), 26-29. https://doi.org/10.2136/sssaj1993.03615995005700010006x

Rossi, C., \& Nimmo, J. R. (1994). Modeling of soil water retention from saturation to oven dryness. Water Resources Research, 30(3), 701-708. https://doi.org/10.1029/93WR03238

Rudiyanto, M. S., van Genuchten, M. T., Alazba, A., Setiawan, B. I., \& Minasny, B. (2015). A complete soil hydraulic model accounting for capillary and adsorptive water retention, capillary and film conductivity, and hysteresis. Water Resources Research, 51, 8757-8772. https://doi.org/10.1002/2015WR017703

Saito, H., Simunek, J., \& Mohanty, B. P. (2006). Numerical analysis of coupled water, vapor, and heat transport in the vadose zone. Vadose Zone Journal, 5(2), 784-800. https://doi.org/10.2136/vzj2006.0007

Schaap, M., \& Leij, F. (2000). Improved prediction of unsaturated hydraulic conductivity with the Mualem- van Genuchten model. Soil Science Society of America Journal, 64(3), 843-851. https://doi.org/10.2136/sssaj2000.643843x

Schaap, M. G., \& van Genuchten, M. T. (2006). A modified Mualem-van Genuchten formulation for improved description of the hydraulic conductivity near saturation. Vadose Zone Journal, 5(1), 27-34. https://doi.org/10.2136/vzj2005.0005

Scharnagl, B., Vrugt, J. A., Vereecken, H., \& Herbst, M. (2011). Inverse modelling of in situ soil water dynamics: Investigating the effect of different prior distributions of the soil hydraulic parameters. Hydrology and Earth System Sciences, 15(10), 3043-3059. https://doi.org/ 10.5194/hess-15-3043-2011

Schelle, H., Heise, L., Jänicke, K., \& Durner, W. (2013). Water retention characteristics of soils over the whole moisture range: A comparison of laboratory methods. European Journal of Soil Science, 64(6), 814-821. https://doi.org/10.1111/ejss.12108

Schindler, U. 2016. Soil hydraulic functions of horticultural substrates, Leibniz-Zentrum für Agrarlandschaftsforschung (ZALF) e.V. doi: https://doi.org/10.4228/ZALF.2015.278

Schindler, U., Durner, W., von Unold, G., \& Müller, L. (2010). Evaporation method for measuring unsaturated hydraulic properties of soils: Extending the measurement range. Soil Science Society of America Journal, 74(4), 1071-1083. https://doi.org/10.2136/ sssaj2008.0358

Schindler, U., \& Müller, L. (2010). Data of hydraulic properties of north east and north central German soils. Earth System Science Data, 2(2), 189-194. https://doi.org/10.5194/essd-2-189-2010

Schindler, U., \& Müller, L. (2015). Soil hydraulic functions of international soils measured with the extended evaporation method (EEM) and the HYPROP device, Leibniz-Zentrum für Agrarlandschaftsforschung (ZALF) e.V. https://doi.org/10.4228/ZALF.2003.273

Schneider, M., \& Goss, K.-U. (2012). Prediction of the water sorption isotherm in air dry soils. Geoderma, 170, 64-69. https://doi.org/ 10.1016/j.geoderma.2011.10.008

Šimůnek, J., Jarvis, N. J., van Genuchten, M. T., \& Gärdenäs, A. (2003). Review and comparison of models for describing non-equilibrium and preferential flow and transport in the vadose zone. Journal of Hydrology, 272(1-4), 14-35. https://doi.org/10.1016/S00221694(02)00252-4

Šimůnek, J., van Genuchten, M. T., \& Miroslav, S. (2016). Recent developments and applications of the HYDRUS computer software packages. Vadose Zone Journal, 15(7). https://doi.org/10.2136/vzj2016.04.0033 
Tokunaga, T. K. (2009). Hydraulic properties of adsorbed water films in unsaturated porous media. Water Resources Research, 45, W06415. https://doi.org/10.1029/2009WR007734

Tóth, B., Weynants, M., Nemes, A., Makó, A., Bilas, G., \& Tóth, G. (2015). New generation of hydraulic pedotransfer functions for Europe. European Journal of Soil Science, 66(1), 226-238. https://doi.org/10.1111/ejss.12192

Tuller, M., \& Or, D. (2001). Hydraulic conductivity of variably saturated porous media: Film and corner flow in angular pore space. Water Resources Research, 37(5), 1257-1276. https://doi.org/10.1029/2000WR900328

van Genuchten, M. T. (1980). Closed-form equation for predicting the hydraulic conductivity of unsaturated soils. Soil Science Society of America Journal, 44(5), 892-898. https://doi.org/10.2136/sssaj1980.03615995004400050002x

Vereecken, H., Maes, J., Feyen, J., \& Darius, P. (1989). Estimating the soil moisture retention characteristic from texture, bulk density and carbon content. Soil Science, 148(6), 389-403. https://doi.org/10.1097/00010694-198912000-00001

Vereecken, H., Schnepf, A., Hopmans, J. W., Javaux, M., Or, D., Roose, T., et al. (2016). Modeling soil processes: Review, key challenges, and new perspectives. Vadose Zone Journal, 15(5), 0. https://doi.org/10.2136/vzj2015.09.0131

Vogel, T., van Genuchten, M. T., \& Cislerova, M. (2000). Effect of the shape of the soil hydraulic functions near saturation on variablysaturated flow predictions. Advances in Water Resources, 24(2), 133-144. https://doi.org/10.1016/S0309-1708(00)00037-3

Volk, E., Iden, S. C., Furman, A., Durner, W., \& Rosenzweig, R. (2016). Biofilm effect on soil hydraulic properties: Experimental investigation using soil-grown real biofilm. Water Resources Research, 52, 5813-5828. https://doi.org/10.1002/2016WR018866

Weber, T. K. D., Gerling, L., Reineke, D., Weber, S., Durner, W., \& Iden, S. C. (2018). Robust inverse modeling of growing season net ecosystem exchange in a mountainous peatland: Influence of distributional assumptions on estimated parameters and total carbon fluxes. Journal of Advances in Modeling Earth Systems, 10. https://doi.org/10.1029/2017MS001044

Weber, T. K. D., Iden, S. C., \& Durner, W. (2017a). Unsaturated hydraulic properties of Sphagnum moss and peat reveal trimodal pore size distributions. Water Resources Research, 53, 415-434. https://doi.org/10.1002/2016WR019707

Weber, T. K. D., Iden, S. C., \& Durner, W. (2017b). Peatland bog pedogenesis is reflected in unsaturated hydraulic properties. Hydrology and Earth System Sciences Discussions, 1-29. https://doi.org/10.5194/hess-2017-297

Weiss, R., Alm, J., Laiho, R., \& Laine, J. (1998). Modeling moisture retention in peat soils. Soil Science Society of America Journal, 62(2), 305-313. https://doi.org/10.2136/sssaj1998.03615995006200020002x

Weynants, M., Vereecken, H., \& Javaux, M. (2009). Revisiting Vereecken pedotransfer functions: Introducing a closed-form hydraulic model. Vadose Zone Journal, 8(1), 86. https://doi.org/10.2136/vzj2008.0062

White, T., Brantley, S., Banwart, S., Chorover, J., Dietrich, W., Derry, L., et al. (2015). Chapter 2-The role of critical zone observatories in critical zone science. Developments in Earth Surface Processes, 19, 15-78. https://doi.org/10.1016/B978-0-444-63369-9.00002-1

Wilson, G. V., Jardine, P. M., \& Gwo, J. P. (1992). Modeling the hydraulic properties of a multiregion soil. Soil Science Society of America Journal, 56(6), 1731-1737. https://doi.org/10.2136/sssaj1992.03615995005600060012x

Xu, X., Nieber, J. L., \& Gupta, S. C. (1992). Compaction effect on the gas diffusion coefficient in soils. Soil Science Society of America Journal, 56(6), 1743-1750. https://doi.org/10.2136/sssaj1992.03615995005600060014x

Zhang, Z. F. (2011). Soil water retention and relative permeability for conditions from oven-dry to full saturation. Vadose Zone Journal, 10(4), 1299-1308. https://doi.org/10.2136/vzj2011.0019 